\title{
Implementation and validation of a strain rate dependent anisotropic continuum model for masonry
}

\author{
S. Hashemi Rafsanjani a,1, P.B. Lourenço ${ }^{\text {a,2 }}$, N. Peixinho ${ }^{\text {b,3 }}$ \\ aSISE, University of Minho, Department of Civil Engineering, Azurém, 4800-058 \\ Guimarães, Portugal \\ ${ }^{\mathrm{b}} \mathrm{CT2M}$, University of Minho, Department of Mechanical Engineering, Azurém, 4800-058 \\ Guimarães, Portugal
}

${ }^{1}$ (Corresponding author) PhD Candidate, ISISE, University of Minho, Department of Civil Engineering, Azurém, 4800-058 Guimarães, Portugal. Tel.: +351 910775 946; fax: +351 253 510 217. E-mail: b6000@civil.uminho.pt

${ }^{2}$ Professor, ISISE, University of Minho, Department of Civil Engineering, Azurém, 4800058 Guimarães, Portugal. Tel.: +351 253510 209; fax: +351 253510 217. E-mail: pbl@civil.uminho.pt

${ }^{3}$ Assistant Professor, CT2M, University of Minho, Department of Mechanical Engineering, Azurém, 4800-058 Guimarães, Portugal. Tel.: +351 253510 220; fax: +351 253516 007. Email: Peixinho@dem.uminho.pt 


\begin{abstract}
A newly developed strain rate dependent anisotropic continuum model is proposed for impact and blast applications in masonry. The present model adopted the usual approach of considering different yield criteria in tension and compression. The analysis of unreinforced block work masonry walls subjected to impact is carried out to validate the capability of the model. Comparison of the numerical predictions and test data revealed good agreement. Next, a parametric study is conducted to evaluate the influence of the tensile strengths along the three orthogonal directions and of the wall thickness on the global behavior of masonry walls.
\end{abstract}

Key words: Block work masonry; impact; continuum model; anisotropy; out of plane response; dynamic increase factor

\title{
1 Introduction
}

Masonry is composed of individual units laid in and bond by mortar at bed and head joints, and has been widely used in different forms of construction and several parts of modern or historical structures. Due to the low seismic performance of masonry structures, in recent decades, a series of investigations have been conducted to improve the dynamic response of such structures. Moreover, after Oklahoma City bombing in 1995, studies dealing with the blast response of structures received increasing interest by the scientific community given the high vulnerability of masonry structures against such destructive loads. A great deal of effort accounting for experiments and numerical simulations has been performed to better understand masonry subjected to high strain rate loads, to advance the retrofitting techniques and to update available design codes. An important objective was to reduce the structural damage and to enhance the blast resistance of existing structures. 
Recently, the evaluation of the performance and the blast response of masonry walls, including the maximum deflection, possible crack distribution and mechanisms of collapse, and damage level have been addressed by different authors. Baylot et al. [1] reported the dominant failure modes of unreinforced concrete masonry unit walls (CMU walls) subjected to blast loading. Failure in mortar joints at the mid-height over the entire length, led to the wall rotation at the bottom edge, and occurrence of diagonal cracking and vertical cracks at the centerline to each side were noted. Bond failure at the mortar joint and overturning along mid-height were also reported in the study by Dennis et al. [2], as mechanisms of collapse of CMU walls. Eamon et al. [3] classified the blast response of CMU walls into three groups in accordance with the magnitude range of pressure. In moderate and high pressure load, the entire wall was broken in one or two horizontal lines and was divided into two or three parts, whereas in case of low pressure load, the wall was broken in a long crack at mid-height, but no remarkable rotation was noticed. The crack formations of unreinforced masonry walls subjected to lower velocity impacts were also categorized by Gilbert et al. [4] into two categories regarding the time of formation.

As high strain rate effects on structures are generally ignored in design rules, several tests have been carried out to study retrofitting techniques to improve masonry walls’ performance and blast behavior, despite the large cost of laboratory tests. Bonding FRP to the back of the wall, applying sprayed-on polyurea on back of the wall, and placing a sheet of steel behind the wall are retrofitting techniques applied by Baylot et al. [1] to improve the blast response of CMU walls. In spite of the acceptable performance of the adopted retrofitting methods, improvements were also proposed to eliminate the difficulties while using them. Myers et al. [5] carried out a series of tests on retrofitted masonry walls with GFRP rods and wide GFRP strips subjected to increasing intensity blast tests. These resulted in a reduction in debris scatter and at least a 50\% increase in peak pressure resistance. The application of sprayed-on 
polymer retrofit for strengthening masonry walls against blast loads was studied by Davidson et al. [6]. Appropriate performance of this technique was found, in case of low and moderate detonation.

Computers allow to describe the dynamic response and localized damage of masonry structures more in detail through numerical simulations. Two common strategies, namely macro strategy and micro strategy, have been used for numerical modeling of masonry, see e.g. Lourenço [7]. Each strategy has its own advantages and disadvantages with respect to accuracy, reliability, computational costs, better understanding of local behavior, and userfriendly mesh generation. The micro approach results in a more accurate representation of the behavior of a masonry with detailed failure mechanisms of the components, while in a macro approach the global behavior of the structure is usually of concern.

A series of studies have been dedicated to introduce the most applied parameters in recent sensitivity studies, and to address their effectiveness on high strain rate behavior of masonry walls. In an investigation by Milani et al. [8] for blast analysis of enclosure masonry walls, a parametric analysis was carried out to evaluate the effect of different wall thicknesses, mortar joint tensile strengths, and dynamic pressures corresponding to blast loads (in kilograms of TNT), ranging from small to large. As expected, the maximum displacement decreases sensibly, when high-strength mortar, thicker walls or lower blast pressure are adopted. Eamon [9], as well, performed a parametric study for CMU walls. As a result, a chart was obtained to detect parameters governing the wall behavior at three different significant hazard levels.

The present study aims to develop a rate dependent anisotropic continuum model for numerical simulation of the high strain rate response of masonry walls using the finite element (FE) code ABAQUS. The developed 3D material model benefits from the idea of 
combining a Rankine type yield criterion in tension and a Hill type yield criterion in compression, including three surfaces for tension and one ellipsoid shaped surface for compression. The continuum model, developed as a user-defined subroutine, is implemented into ABAQUS and attributed to 3D solid elements to simulate the masonry behavior. The macro approach is involved in the numerical modeling of masonry walls. The obtained results are compared with test data to evaluate the accuracy of the proposed material model to numerically predict the structural damage and response of masonry walls subjected to high strain rate loads. Furthermore, a parametric study is also conducted to discuss the influence of dominant parameters on the global behavior of masonry walls.

\section{An anisotropic continuum model for high strain rates}

Recently, a series of studies have been carried out to develop high strain rate constitutive material models for several materials, including masonry. Wei and Stewart [10] proposed a damage dependent piecewise Drucker-Prager strength criterion for continuum modeling of brick and mortar, used in a micro-model to simulate the blast response of masonry walls. A simple rigid-perfectly plastic homogenization masonry model, characterized by a few material parameters and numerically inexpensive and robust, was presented by Milani et al. [11] for micro numerical simulation of masonry structures subjected to out-of plane high strain rate loads. The proposed model was implemented in a finite element thin plate triangular element.

The present study presents a plastic stain rate dependent continuum model, which obeys a non-associated flow rule to characterize the masonry behavior at high strain rates. The newly developed model benefits from advantages of a powerful representation of anisotropic material behavior (i.e. different hardening/softening behavior is defined along each material axis) and follows the previous approach of making a composite yield surface considering 
individual inelastic criteria in tension and compression to model the orthotropic material behavior, see Lourenço [7] for a review. The proposed model is composed of three Rankine type yield criteria in tension, using pairs of normal and shear stresses, and a Hill type yield criterion in compression, see Fig. 1. The formulation is presented in the 3D stress space, with six stress components. For a 3D configuration, the stress vector, strain vector, and the compliance matrix are given as

$$
\begin{aligned}
& \sigma=\left\{\sigma_{x}, \sigma_{y}, \sigma_{z}, \tau_{x y}, \tau_{y z}, \tau_{x z}\right\}^{T} \\
& \varepsilon=\left\{\varepsilon_{x}, \varepsilon_{y}, \varepsilon_{z}, \gamma_{x y}, \gamma_{y z}, \gamma_{x z}\right\}^{T}
\end{aligned}
$$

$$
C=D^{-1}=\left[\begin{array}{cccccc}
\frac{1}{E_{x}} & \frac{-v_{x y}}{E_{y}} & \frac{-v_{z x}}{E_{z}} & 0 & 0 & 0 \\
& \frac{1}{E_{y}} & \frac{-v_{z y}}{E_{z}} & 0 & 0 & 0 \\
& \frac{1}{E_{z}} & 0 & 0 & 0 \\
& & \frac{1}{2 G_{x y}} & 0 & 0 \\
& & & \frac{1}{2 G_{y z}} & 0 \\
& & & & & \frac{1}{2 G_{x z}}
\end{array}\right]
$$

Where, $\sigma$ is stress vector and $\varepsilon$ is strain vector. $C$ denotes the compliance matrix and $D$ is the symmetric orthotropic elasticity matrix. For an orthotropic material, the three symmetry planes namely $x y, y z$, and $x z$ include nine independent elastic moduli. $E_{i}$ and $G_{j k}(i=x, y$ or $z$ and $j k=x y, y z$ or $x z$ ) are the three Young's moduli and three shear moduli, respectively, and $v_{\mathrm{jk}}$ are the three Poisson's ratios. 


\subsection{Tensile mode}

Considering the high strain effects on the continuum material model, the dynamic increase factors (DIFs), which is the ratio of dynamic to static parameters' values, are applied to most likely dominant material parameters to expand or to contract the failure envelope at different strain rates. The orthotropic Rankine type yield criteria for tension in $x y, y z$, and $x z$ symmetric planes, labeled now as $i=1,2$, and 3 respectively, are introduced in terms of $k_{t}, \mathrm{i}$, stress components, and $\alpha_{\mathrm{i}}$. The parameter $k_{t}$ is a scalar to control the composite yield surface by measuring the amount of softening in each material axes and is a measure of the inelastic process. The parameter $\alpha$ controls the contribution of shear stress to failure. Also, the subscripts $x, y, z$ refer to the material axes.

In the following equations, the subscript $i$ refers to the yield surface label.

$$
\begin{aligned}
& f_{1}=\frac{\left(\sigma_{x}-\bar{\sigma}_{t x}\left(k_{t, 1}\right)\right)+\left(\sigma_{y}-\bar{\sigma}_{t y}\left(k_{t, 1}\right)\right)}{2}+\sqrt{\left[\frac{\left(\sigma_{x}-\bar{\sigma}_{t x}\left(k_{t, 1}\right)\right)-\left(\sigma_{y}-\bar{\sigma}_{t y}\left(k_{t, 1}\right)\right)}{2}\right]^{2}+\alpha_{1} \tau_{x y}^{2}} ; \alpha_{1}=\frac{f_{t x} f_{t y}}{\tau_{u}^{2}} \\
& f_{2}=\frac{\left(\sigma_{y}-\bar{\sigma}_{t y}\left(k_{t, 2}\right)\right)+\left(\sigma_{z}-\bar{\sigma}_{t z}\left(k_{t, 2}\right)\right)}{2}+\sqrt{\left[\frac{\left(\sigma_{y}-\bar{\sigma}_{t y}\left(k_{t, 2}\right)\right)-\left(\sigma_{z}-\bar{\sigma}_{t z}\left(k_{t, 2}\right)\right)}{2}\right]^{2}+\alpha_{2} \tau_{y z}^{2}} ; \alpha_{2}=\frac{f_{t y} f_{t z}}{\tau_{u}^{2}} \\
& f_{3}=\frac{\left(\sigma_{x}-\bar{\sigma}_{t x}\left(k_{t, 3}\right)\right)+\left(\sigma_{z}-\bar{\sigma}_{t z}\left(k_{t, 3}\right)\right)}{2}+\sqrt{\left[\frac{\left(\sigma_{x}-\bar{\sigma}_{t x}\left(k_{t, 3}\right)\right)-\left(\sigma_{z}-\bar{\sigma}_{t z}\left(k_{t, 3}\right)\right)}{2}\right]^{2}+\alpha_{3} \tau_{x z}^{2}} ; \alpha_{3}=\frac{f_{t x} f_{t z}}{\tau_{u}^{2}}
\end{aligned}
$$

The yield values that follow exponential tensile softening rules, with different fracture energies along each axis are expressed as

$$
\bar{\sigma}_{t x}\left(k_{t, i}\right)=f_{t x} \exp \left(-\frac{h f_{t x}}{G_{f t x}} k_{t, i}\right) \quad \bar{\sigma}_{t y}\left(k_{t, i}\right)=f_{t y} \exp \left(-\frac{h f_{t y}}{G_{f t y}} k_{t, i}\right) \quad \bar{\sigma}_{t z}\left(k_{t, i}\right)=f_{t z} \exp \left(-\frac{h f_{t z}}{G_{f t z}} k_{t, i}\right)
$$

Here, $f_{t x}, f_{t y}$, and $f_{t z}$ are the material uniaxial tensile strength, and $G_{f t x}, G_{f t y}, G_{f t z}$ are the material tensile fracture energy along the material axes. The parameter $h$ denotes the equivalent length and is associated with the area of an element by, see [12]. 
$h=\alpha_{h} \sqrt{A_{e}}=\alpha_{h}\left(\sum_{\xi=1}^{\eta_{\xi}} \sum_{\eta=1}^{\eta_{\eta}} \operatorname{det}(J) w_{\xi} w_{\eta}\right)^{1 / 2}$

in which $\alpha_{h}$ is a modification factor and is assumed equal to $\sqrt{2}$ for linear elements, see [13]. $w_{\xi}$ and $w_{\eta}$ are the weight factors in Gaussian integration rule. In order to eliminate the snap-back at constitutive level, in case of large element size, to obtain a pronounced step in brittle failure, the following condition is required to be satisfied, see Rots [13],

$h \leq \frac{G_{f t i} E_{i}}{f_{t i}^{2}}$

In case of violating this condition for any of the material axes, the respective tensile strength $f_{t i}$ is revised to

$f_{t i}=\left(\frac{G_{f t i} E_{i}}{h}\right)^{1 / 2}$

The expressions for the Rankine type yield criterion can be recast in a matrix form as

$f_{i}=\left(1 / 2 \xi_{i}^{T} P_{t, i} \xi_{i}\right)^{1 / 2}+1 / 2 \pi_{i}^{T} \xi_{i}$

where, $\xi_{i}$ is the reduced stress vector and reads

$\xi_{i}=\sigma-\eta_{i}$

The back stress vector $\eta_{i}$ reads

$$
\begin{aligned}
& \eta_{1}=\left\{\bar{\sigma}_{t x}\left(k_{t, 1}\right), \bar{\sigma}_{t y}\left(k_{t, 1}\right), 0,0,0,0\right\}^{T} \\
& \eta_{2}=\left\{0, \bar{\sigma}_{t y}\left(k_{t, 2}\right), \bar{\sigma}_{t z}\left(k_{t, 2}\right), 0,0,0\right\}^{T}
\end{aligned}
$$


$\eta_{3}=\left\{\bar{\sigma}_{t x}\left(k_{t, 3}\right), 0, \bar{\sigma}_{t z}\left(k_{t, 3}\right), 0,0,0\right\}^{T}$

The projection matrix $P_{t, i}$ reads

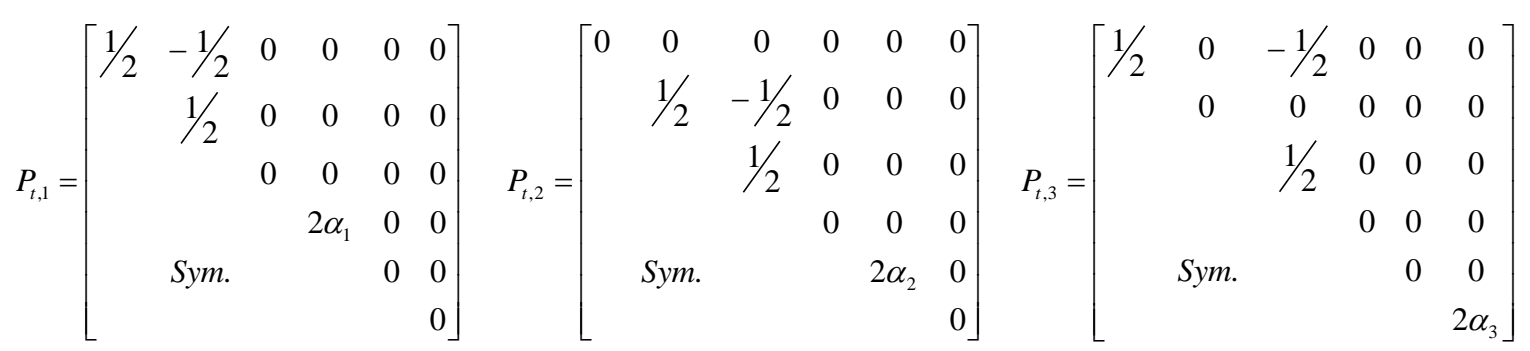

The projection vector $\pi_{i}$ reads

$$
\begin{aligned}
& \pi_{1}=\{1,1,0,0,0,0\}^{T} \\
& \pi_{2}=\{0,1,1,0,0,0\}^{T} \\
& \pi_{3}=\{1,0,1,0,0,0\}^{T}
\end{aligned}
$$

Involving the high strain rate effects, the DIFs are applied to the uniaxial tensile strength and the fracture energy along the material axes to obtain

$$
\begin{aligned}
& f_{t j}=D I F \times f_{t j_{0}} \\
& G_{f t j}=D I F \times G_{f t j_{0}}
\end{aligned}
$$

where, $f_{t j_{0}}$ and $G_{f t j_{0}}$ are the quasi-static strength and fracture energy under uniaxial tension in different directions, respectively. The subscript $j$ refers to the material axis $x, y$ and $z$.

The non-associated plastic potential $g_{i}$ is considered as

$$
g_{i}=\left(1 / 2 \xi_{i}^{T} P_{g, i} \xi_{i}\right)^{1 / 2}+1 / 2 \pi_{i}^{T} \xi_{i}
$$


Here, the projection matrix $P_{g, i}$ to represent the Rankine plastic flow is given as

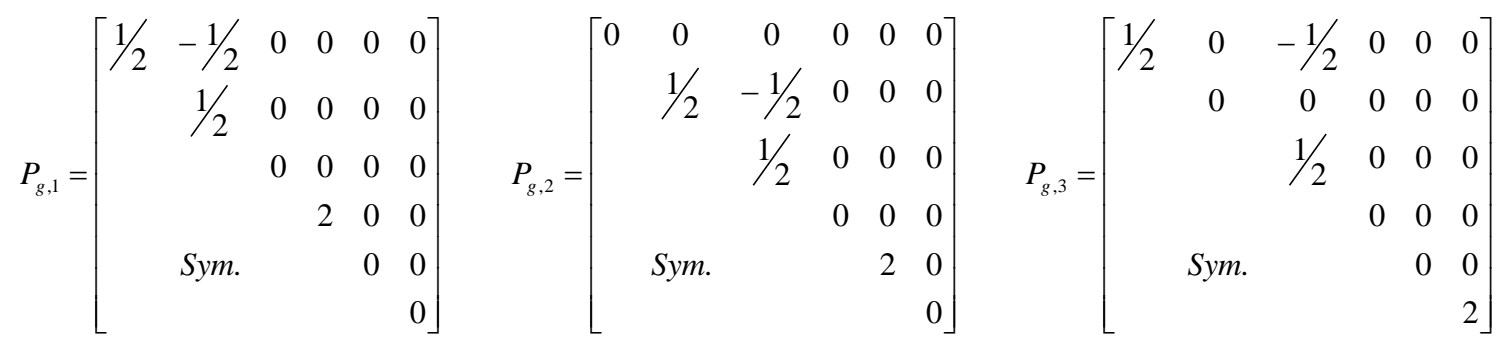

In case of strain softening to describe the inelastic behavior, the scalar $\dot{k}_{t, i}$ is given, in rate form, in terms of maximum principal plastic strain, recast in a matrix form, and expressed as

$$
\dot{k}_{t, i}=\left(1 / 2\left(\dot{\varepsilon}^{p}\right)^{T} Q_{i} \dot{\varepsilon}^{p}\right)^{1 / 2}+1 / 2 \pi_{i}^{T} \dot{\varepsilon}^{p}
$$

where

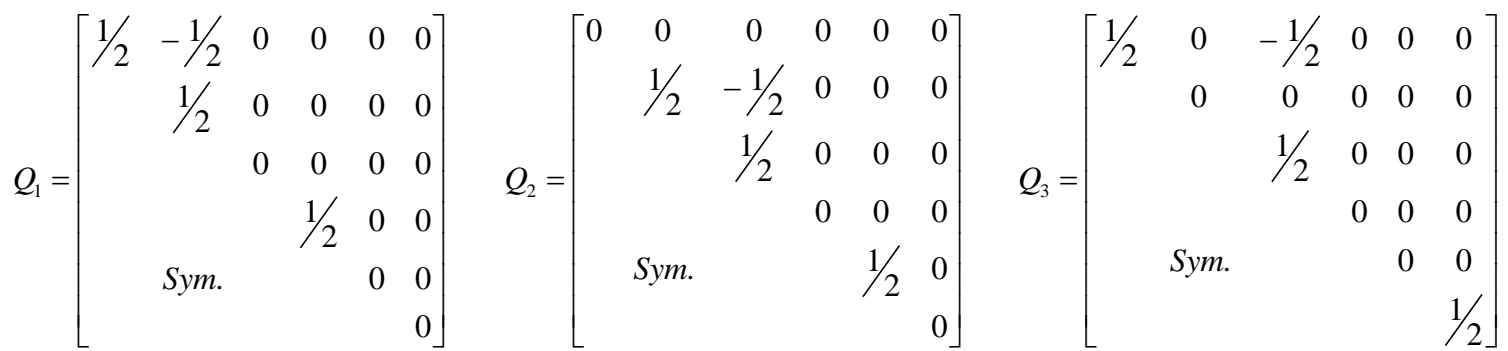

After manipulation, Eq. (20) reduces to the following particularly simple expression

$\dot{k}_{t, i}=\dot{\lambda}_{t, i}$

In which $\dot{\lambda}_{t, i}$ is the plastic multiplier rate.

When the trial stress violates the yield surface, the plastic corrector brings back the stress update to the yield surface. Having the stress updating equations and failure criteria, a nonlinear system of equations with several unknowns is established and solved by using an iterative Newton-Raphson method. In every integration point during the iterations at each increment the return mapping algorithm results in updating the stress vector and user-state 
variables. In a plasticity model, assuming the elastic stress value in the first iteration, a trial value is assumed for stress such as $\sigma_{n+1}=\sigma^{t r i a l}, \dot{k}_{t}{ }_{n+1}=0$, and $\dot{\lambda}_{t}{ }^{n+1}=0$, which is obtained by the elastic predictor. The unknowns of the nonlinear system of equations that arise in this update procedure are the stress components, $\dot{k}_{t}{ }_{n+1}$ and $\dot{\lambda}_{t}{ }^{n+1}$. The stress update equations for a finite step are given by

$$
\sigma_{n+1}=\sigma^{t r i a l}-D \dot{\varepsilon}_{n+1}^{p}
$$

with $\sigma^{\text {trial }}=\sigma_{n}+D \dot{\varepsilon}_{n+1}$. The stress update equations can be easily obtained from the set of non-linear equations system

$$
\left\{\begin{array}{l}
D^{-1}\left(\sigma_{n+1}-\sigma^{\text {trial }}\right)+\left.\dot{\lambda}_{t, i^{n+1}} \frac{\partial g_{i}}{\partial \sigma}\right|_{n+1}=0 \\
f_{i n+1}=\left(1 / 2 \xi_{i^{n+1}}^{T} P_{t, i n+1} \xi_{i^{n+1}}\right)^{1 / 2}+1 / 2 \pi^{T} \xi_{i^{n+1}}=0
\end{array}\right.
$$

where,

$$
\frac{\partial g_{i}}{\partial \sigma}=\frac{P_{g, i} \xi_{i n+1}}{2\left(1 / 2 \xi_{i n+1}^{T} P_{g, i} \xi_{i n+1}\right)^{1 / 2}}+1 / 2 \pi
$$

The Jacobian required for the iterative local Newton-Raphson method is obtained and reported in [14]. However, the gradient of the plastic potential in Eq. (25) is not defined for the entire stress domain. As shown in Fig. 1, the intersection of three perpendicular Rankine type yield surfaces defines one apex and three edges, in which the numerical algorithm is not stable. Lourenço [7] implemented a simple algorithm to solve the difficulty dealing with nondefined gradient in the apex and edges. For the apex regime, the three shear stress components, namely $\tau_{x y}, \tau_{y z}$, and $\tau_{x z}$ are equal to zero. Independent from the trial stress, the 
stress update is assumed to return to the apex, which is sufficient to fulfill $f_{1^{n+1}}=0, f_{2^{n+1}}=0$ , and $f_{3 n+1}=0$, given by

$$
\sigma_{n+1}=\left\{\bar{\sigma}_{t x}\left(\max \left(k_{t, 1}, k_{t, 3}\right)\right), \bar{\sigma}_{t y}\left(\max \left(k_{t, 1}, k_{t, 2}\right)\right), \bar{\sigma}_{t z}\left(\max \left(k_{t, 2}, k_{t, 3}\right)\right), 0,0,0\right\}^{T}
$$

The following non-linear equation is then obtained to update the softening scalar, $\dot{k}_{t, i}$

$$
F\left(\dot{k}_{t, i} n+1\right)=\dot{k}_{t, i}^{n+1}-\left(1 / 2\left(\dot{\varepsilon}_{n+1}^{p}\right)^{T} Q_{i} \dot{\varepsilon}_{n+1}^{p}\right)^{1 / 2}-1 / 2 \pi_{i}^{T} \dot{\varepsilon}_{n+1}^{p}
$$

with $\dot{\varepsilon}_{n+1}^{p}=D^{-1}\left(\sigma^{\text {trial }}-\sigma_{n+1}\right)$.

Along the three edges, for the intersection between the 3 and 2 planes, labeled $A, \tau_{x y}=0$. $\tau_{y z}=0$ is assumed for the intersection of 1 and 3 surfaces, labeled $B$, and $\tau_{x z}=0$ is assumed for the intersection between the 1 and 2 surfaces, labeled $C$.

For the edges $A, B$, and $C$, the stress update for each return mapping is then given by

$$
\begin{aligned}
& \sigma_{A^{n+1}}=\left\{\bar{\sigma}_{t x}\left(k_{t, 1}\right), \bar{\sigma}_{t y}\left(k_{t, 1}\right), \sigma_{z}^{t r i a l}, 0, \tau_{y z}^{\text {trial }}, \tau_{x z}^{t r i a l}\right\}^{T} \\
& \sigma_{B^{n+1}}=\left\{\sigma_{x}^{t r i a l}, \bar{\sigma}_{t y}\left(k_{t, 2}\right), \bar{\sigma}_{t z}\left(k_{t, 2}\right), \tau_{x y}^{t r i a l}, 0, \tau_{x z}^{t r i a l}\right\}^{T} \\
& \sigma_{c^{n+1}}=\left\{\bar{\sigma}_{t x}\left(k_{t, 3}\right), \sigma_{y}^{t r i a l}, \bar{\sigma}_{t z}\left(k_{t, 3}\right), \tau_{x y}^{t r i a l}, \tau_{y z}^{t r i a l}, 0\right\}^{T}
\end{aligned}
$$

The non-linear equations used to update the softening scalars for the edges $A, B$, and $C$, are expressed as, where the subscribe $j$ refers to the edge label,

$$
F_{j}\left(\dot{k}_{t, i n+1}\right)=\dot{k}_{t, i} n+1-\left(1 / 2\left(\dot{\varepsilon}_{n+1}^{p}\right)^{T} Q_{i} \dot{\varepsilon}_{n+1}^{p}\right)^{1 / 2}-1 / 2 \pi_{i}^{T} \dot{\varepsilon}_{n+1}^{p}
$$

\subsection{Compression mode}

In the present study, a rotated centered ellipsoid shape Hill type yield criterion is adopted in the full 3D stress space with six stress components to characterize the masonry behavior in compression. Using matrix notation, the orthotropic Hill type yield criterion is expressed in a 
cube root matrix form more compatible for numerical implementation, and is given as follows

$$
f_{4}=\left(1 / 2 \sigma^{T} P_{c} \sigma\right)^{1 / 3}-\bar{\sigma}_{c}\left(k_{c}\right)
$$

where the scalar $k_{c}$ measures the amount of hardening/softening along the material axes, and the yield value $\bar{\sigma}_{c}$ reads as the product of the yield value along the three material axes with subscript $x, y$ and $z$,

$$
\bar{\sigma}_{c}\left(k_{c}\right)=\sqrt[3]{\bar{\sigma}_{c x}\left(k_{c}\right) \bar{\sigma}_{c y}\left(k_{c}\right) \bar{\sigma}_{c z}\left(k_{c}\right)}
$$

The projection matrix $P_{c}$ reads

$$
P_{c}=\left[\begin{array}{cccccc}
G^{\prime}+H^{\prime} & -H^{\prime} & -G^{\prime} & 0 & 0 & 0 \\
& F^{\prime}+H^{\prime} & -F^{\prime} & 0 & 0 & 0 \\
& & F^{\prime}+G^{\prime} & 0 & 0 & 0 \\
& & & 2 N^{\prime} & 0 & 0 \\
& \text { Sym. } & & & 2 L^{\prime} & 0 \\
& & & & & 2 M^{\prime}
\end{array}\right]
$$

in which, $G^{\prime}=\left[\frac{\bar{\sigma}_{c x} \bar{\sigma}_{c y}}{\bar{\sigma}_{c z}}+\frac{\bar{\sigma}_{c y} \bar{\sigma}_{c z}}{\bar{\sigma}_{c x}}-\frac{\bar{\sigma}_{c x} \bar{\sigma}_{c z}}{\bar{\sigma}_{c y}}\right], F^{\prime}=\left[\frac{\bar{\sigma}_{c x} \bar{\sigma}_{c z}}{\bar{\sigma}_{c y}}+\frac{\bar{\sigma}_{c x} \bar{\sigma}_{c y}}{\bar{\sigma}_{c z}}-\frac{\bar{\sigma}_{c y} \bar{\sigma}_{c z}}{\bar{\sigma}_{c x}}\right]$,

$$
H^{\prime}=\left[\frac{\bar{\sigma}_{c y} \bar{\sigma}_{c z}}{\bar{\sigma}_{c x}}+\frac{\bar{\sigma}_{c x} \bar{\sigma}_{c z}}{\bar{\sigma}_{c y}}-\frac{\bar{\sigma}_{c x} \bar{\sigma}_{c y}}{\bar{\sigma}_{c z}}\right], N^{\prime}=\bar{\sigma}_{c z} \gamma_{x y}, L^{\prime}=\bar{\sigma}_{c x} \gamma_{y z} \text {, and } M^{\prime}=\bar{\sigma}_{c y} \gamma_{x z} \text {. }
$$

The parameters $\gamma_{x y}, \gamma_{y z}$, and $\gamma_{x z}$ are used to control the shear stress contribution to failure and are given by $\gamma_{x y}=\frac{f_{m x} f_{m y}}{\tau_{u}{ }^{2}}, \gamma_{y z}=\frac{f_{m y} f_{m z}}{\tau_{u}{ }^{2}}$, and $\gamma_{x z}=\frac{f_{m x} f_{m z}}{\tau_{u}{ }^{2}} \cdot f_{m x}, f_{m y}$, and $f_{m z}$ are the material uniaxial compressive strength along the material axes and $\tau_{u}$ is the material pure shear strength. 
In order to follow the exponential compressive hardening/softening rules, the subsequent law is involved as

$$
\begin{aligned}
& \bar{\sigma}_{a}\left(k_{c}\right)=\bar{\sigma}_{i}+\left(\bar{\sigma}_{p}-\bar{\sigma}_{i}\right) \sqrt{\frac{2 k_{c}}{k_{p}}-\frac{k_{c}^{2}}{k_{p}^{2}}} \\
& \bar{\sigma}_{b}\left(k_{c}\right)=\bar{\sigma}_{p}+\left(\bar{\sigma}_{m}-\bar{\sigma}_{p}\right)\left(\frac{k_{c}-k_{p}}{k_{m}-k_{p}}\right)^{2} \\
& \bar{\sigma}_{f}\left(k_{c}\right)=\bar{\sigma}_{r}+\left(\bar{\sigma}_{m}-\bar{\sigma}_{r}\right) \exp \left(m \frac{k_{c}-k_{m}}{\bar{\sigma}_{m}-\bar{\sigma}_{r}}\right)
\end{aligned}
$$

with $m=2 \frac{\bar{\sigma}_{m}-\bar{\sigma}_{p}}{k_{m}-k_{p}}$.

Here, the subscripts $i, m, p$ and $r$ in the yield value and scalar $k$ indicate the initial, medium, peak and residual values, respectively, providing parabolic hardening, followed by exponential softening, see Fig. 2.

The dynamic increase factors of uniaxial compressive strength and hardening are utilized to shift the failure envelop at different strain rates.

$$
\begin{aligned}
& f_{m j}=D I F \times f_{m j_{0}} \\
& G_{f c j}=D I F \times G_{f c j_{0}} \\
& k_{p}=D I F \times k_{p_{0}}
\end{aligned}
$$

Here, $f_{m j_{0}}, G_{f c_{0}}$, and $k_{p_{0}}$ refer to the quasi-static compressive strength, fracture energy, and amount of hardening corresponding to uniaxial compressive strength and scalars defining the inelastic law. The subscript $j$ refers to the material axis. 
Considering an associated flow rule and work hardening/softening hypothesis, this yields to the simple equation

$$
\dot{k}_{c}=\frac{1}{\bar{\sigma}_{c}} \sigma^{T} \dot{\varepsilon}^{p}=\dot{\lambda}_{c}
$$

The Euler backward algorithm reduces to the following non-linear set of equations with seven unknowns, $\sigma_{n+1}$ components and the plastic multiplier $\dot{\lambda}_{c}{ }_{n+1}$

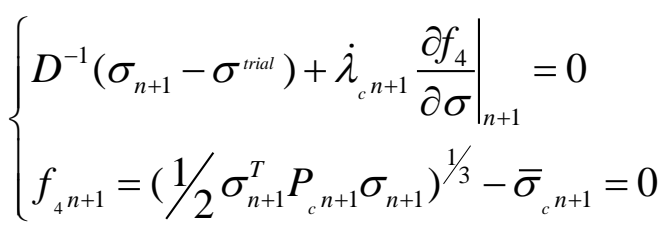

where,

$$
\frac{\partial f_{4}}{\partial \sigma}=\frac{P_{c} \sigma_{n+1}}{3\left(1 / 2 \sigma_{n+1}^{T} P_{c} \sigma_{n+1}\right)^{2 / 3}}
$$

The Jacobian necessary for the iterative local Newton-Raphson method is given in [14].

\subsection{A composite yield criterion}

Regarding the different facets of multiscale plasticity, the different four yield criteria in uncoupled tension and compression regimes are combined in a composite yield surface. As noted in Fig. 3, given the different yield surfaces in tension and compression, the stress domain is divided into different divisions. Despite the possibility of the trial stress being located on apex or three different edges beyond the yield surface, once the trial stress violates the yield surface, depending on its spot, a number of yield surfaces become active. 
The Euler backward algorithm reduces to the following non-linear system of seven to ten equations with seven to ten unknowns, $\sigma_{n+1}$ components and one to four plastic multipliers $\dot{\lambda}_{t, i} n+1$, and $\dot{\lambda}_{c}{ }^{n+1}$, depending on where the trial stress is located

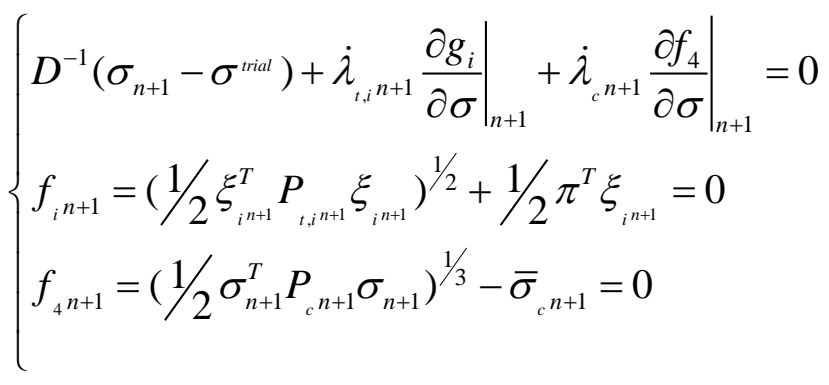

The jacobian necessary for the iterative local Newton-Raphson method is presented [14].

\subsection{Strain rate effects}

A series of studies have been performed to characterize the high strain rate material properties of masonry, resulted in derivation of DIFs. In a study to develop a continuum damage model accounting for the high strain rate effects for masonry based on the homogenization technique, Wei and Hao [15] considered a representative volume element (RVE) submitted to different loading conditions. This allows obtaining dynamic increase factors for most likely dominant material parameters and a failure envelop defined at different strain rate levels. In another investigation, Pereira [16] carried out a study to experimentally characterize the brick, mortar and masonry behavior at high strain rates. The following expressions for DIFs of masonry parameters in terms of strain rate were obtained under drop weight impact loading over a wide range of strain rates.

Regression equation for ultimate compressive strength

$$
\left\{\begin{array}{l}
1 \text { if } 1 E-5 s^{-1}<\dot{\varepsilon} \leq 3 s^{-1} \\
0.2798 \ln \dot{\varepsilon}+0.6863 \text { if } 3 s^{-1}<\dot{\varepsilon} \leq 200 s^{-1}
\end{array}\right.
$$


Regression equation for the Young's modulus

$$
\left\{\begin{array}{l}
1 \text { if } 1 E-5 s^{-1}<\dot{\varepsilon} \leq 1.7 s^{-1} \\
0.2409 \ln \dot{\varepsilon}+0.8701 \text { if } 1.7 s^{-1}<\dot{\varepsilon} \leq 200 s^{-1}
\end{array}\right.
$$

Regression equation for strain corresponding to peak compressive strength

$$
\left\{\begin{array}{l}
1 \text { if } 1 E-5 s^{-1}<\dot{\varepsilon} \leq 4 s^{-1} \\
0.0678 \ln \dot{\varepsilon}+0.9036 \text { if } 4 s^{-1}<\dot{\varepsilon} \leq 200 s^{-1}
\end{array}\right.
$$

Regression equation for compressive fracture energy

$$
\left\{\begin{array}{l}
1 \text { if } 1 E-5 s^{-1}<\dot{\varepsilon} \leq 2 s^{-1} \\
0.4716 \ln \dot{\varepsilon}+0.5968 \text { if } 2 s^{-1}<\dot{\varepsilon} \leq 200 s^{-1}
\end{array}\right.
$$

Fig. 4 shows a summary of DIFs obtained for the masonry parameters. The strain rate has a slight influence on the strain corresponding to peak compressive strength. The influence of strain rate on compressive strength and Young's modulus is similarly addressed. Moreover, increasing the strain rate significantly arises the fracture energy, much more than the compressive strength and Young's modulus.

Given the lack of information associated with the tensile material properties of masonry with increasing strain rates, identical DIFs are assumed for material properties both in tension and compression. The following parameters are those to which the DIFs are applied: $f_{t x}, f_{t y}, f_{t z}$, $G_{f t, x}, G_{f t, y}, G_{f t, z}, f_{m x}, f_{m y}, f_{m z}, G_{f c, x}, G_{f c, y}, G_{f c, z}, k_{p}, E_{x}, E_{y}$, and $E_{z}$.

A VUMAT user-defined subroutine, including the material model, the procedure to update the stress vector and the state variables, is developed to implement the proposed plasticity model in ABAQUS.

\section{Behavior of the model with different strain rates}

In order to illustrate the response of the developed plasticity model in the prediction of masonry behavior and appropriate implementation of user-defined subroutine in ABAQUS, a 
simple numerical model of a cubic element with dimensions of $100 \times 100 \times 100 \mathrm{~mm}$ are developed and submitted under different loading conditions at different strain rates. The material properties adopted for the masonry, and the DIFs proposed by Pereira [16] are given in Table 1 and Table 2. The numerical model and the behavior subjected to each type of loading are given in Fig. 5.

Full agreement is noticed comparing the default material properties introduced as input parameters to the software, with the numerical orthotropic masonry behavior at different strain rates. Hence, the material model and implementation in the user-subroutine in FE code ABAQUS seems to be adequate.

\section{Validation of the constitutive model}

\subsection{Masonry parapets under low velocity impact}

In the present study, the use of dynamic continuum model for numerical analysis of masonry structures is validated by comparing the numerical results with test data of two masonry parapets, namely URP1 and URP2. The two full-scale unreinforced mortar bonded concrete blockwork masonry parapets are subjected to low velocity impacts with different applied impulses, applied by square steel plate located at mid-length [4]. The walls are constructed with two different thicknesses of $200 \mathrm{~mm}$ and $215 \mathrm{~mm}$, and have the clear size of $5.75 \times 1.15 \mathrm{~m}$ and $9.15 \times 1.13 \mathrm{~m}$, respectively. Two different concrete block types were used in tests, but the mortar type was kept constant. The $12 \mathrm{~mm}$ thick steel plates bolted to the strong floor served as supports at the bottom and were jointed with epoxy. Two stiff concrete blocks constructed at the extremes of the walls were utilized as abutments. The abutments were connected to the walls using epoxy mortar precluding the rotation at edges. As noted in the tests, this type of bonding produces fixed boundary condition at three edges. Regarding the 
test data, both abutments are assumed as rigid boundaries in numerical simulation, since no serious damage was noticed in them during the test. The impact load was applied through a $400 \times 400 \times 50 \mathrm{~mm}$ steel plate at mid-height of the wall. The details of the walls and dimensions are shown in Fig. 6. The applied load is simulated by a triangular load-time distribution with peak force of $90 \mathrm{KN}$ and $110 \mathrm{KN}$ reaches at $22.9 \mathrm{msec}$ and $25 \mathrm{msec}$, respectively, see Fig. 7.

For numerical analysis, the rate dependent composite plasticity model is attributed to eightnode linear bricks (reduced integration degenerated solid elements) to consider the masonry behavior along different material axes. A regular fine mesh of cubic elements is used in numerical analysis. There are a total of 3024 and 4788 elements in the numerical models of the walls URP1 and URP2, respectively. The $x, y, z$ axes are along the horizontal, vertical and out of plane directions, respectively. No tests were done to characterize the masonry properties, so the values in Table 3 and Table 4 are obtained from [17]. The material properties are introduced as input parameters in numerical simulations.

\section{Comparison of results}

The predicted impact responses of the walls, URP1 and URP2, accounts for the out of plane displacement vs. time responses and the observed facture lines. The out of plane displacement is recorded at the point placed at mid height, and $580 \mathrm{~mm}$ above the base. The maximum principal plastic strain is adopted as the indicator of the crack distribution. The numerical results are compared to the test data to estimate the accuracy of the predictions. As shown in Fig. 8, the simulated magnitude of peak displacement and the pre-peak and postpeak trends are close to the observed test responses. Even though weaker concrete blocks were used in construction of URP1 and the wall thickness is lower, wall URP2 moves much further given the different applied force-time distribution. Also, the longer length of URP2 
has a significant influence in increasing the out of plane displacement. Here it is noted that for wall URP1 there is a pronounced built up of stiffness found in response due to the inertial forces and acceleration of movement. For the wall URP2, the numerical response is shifted to the origin because the experiment does not show the initial acceleration of movement. The slight reduction observed in displacement vs. time trends is due to the rocking back of the local sections bounded by diagonal cracks connected with the horizontal fracture lines over the length of the wall. Fig. 9 also shows the influence of dynamic properties in numerical results of URP1 compared to the static properties. As noted, using the static properties leads to the significant increase of deformation of the parapet resulting in collapse of the wall.

The observed damages of the parapets against the applied force-time history are addressed in Fig. 10 and Fig. 11. Fig. 12 and Fig. 13 show the predicted behavior of the parapets including the deformed mesh and the front and back face crack distribution at ultimate deflection loaded with out of plane impact. Regarding the predictions, for URP1, the escalation of cracks is noted close to the impact zone along with the front and back face diagonal tensile fracture lines at both sides. The vertical cracks are formed on the wall's centerline and to each side. The horizontal cracks are also distributed at lower levels along the length of the parapet, see Fig. 12. It is noted that the front and back face vertical cracks occur around the centerline of URP2. The diagonal tensile fracture lines are also detected on both sides, often connected by the horizontal cracks to each side. The horizontal cracks formed at the lower levels lead both right and left parts to rotate inside, see Fig. 13. Tracking the crack formation with loading, initially, cracks at the top of the walls were observed, followed by cracks at mid-height. Cracks at the bottom occurred much later, and at last, front face cracks were formed far from the impact zone. As noted, the predictions dealing with the simulated crack patterns are close to the test response, which further validates the results. 
In order to study the performance of URP1 to impact, the structural responses including the displacement vs. time and strain rate vs. time in specific points and time history of strain rate at different stages, namely cracking, reusable, non-reusable, peak are evaluated. The points, labeled A, B and C are located on the centerline at mid-height, three quarter-height, and top of the wall, respectively. The location of the points and impact responses of URP1 at given points are shown in Fig. 14. As noted, the cracking starts from 9 msec and instantly spreads to other parts results in a significant reduction in out of plane resistance of the wall. According to a masonry damage criterion defined by UFC-3-340-02 (2008) [18] (i.e. two levels of damage are defined, namely reusable and non-reusable in accordance with the maximum support rotation of the wall), the masonry parapet is considered non-reusable at 28.2 msec indicating that the wall is severely damaged under impact, and the impact intensity is high enough to apply intense failures on the structure, see Table 5. Up to non-reusable stage, the displacements and strain rates at point A are the least compared with the values in other points and the parameters' values at point B are more than the values in point $\mathrm{C}$. However, the displacements and strain rates at point $\mathrm{C}$ significantly rise after the nonreusable stage and become maximum to the end of the analysis, see Fig. 14(b) and (c). Before the non-reusable stage, the maximum strain rate of $64.7 \mathrm{~S}^{-1}$ occurs at point $\mathrm{A}$ and reaches at 22.8 msec. After this instant at point $\mathrm{C}$, the maximum strain rate of $115 \mathrm{~S}^{-1}$ reaches at 44.7 msec. The strain rate at point A significantly decays to reach $17.48 \mathrm{~S}^{-1}$ at $50.1 \mathrm{msec}$, when the displacement reaches to the peak value of $31 \mathrm{~mm}$. In the time interval between the cracking and peak stages, the peak value of strain rate at each point is noticed. After the peak stage, the strain rate at each point decreases and tends to reach zero at the end of analysis. Regarding the time history of strain rate at certain stages, as expected, the low velocity impact could significantly amplify the strain rate at the center. Therefore, the positive and increasing strain rate growth begins from these zones and widely distributes to other zones up to $28.2 \mathrm{msec}$. 
After non-reusable stage, the strain rate decreases at the center to reach zero at the end of analysis, but as it is shown at the peak stage, the strain rate distribution is still remarkable at the top zone close to the centerline compared to other zones, see Fig. 14(d) and (g).

\subsection{Arching unreinforced concrete masonry walls under free-field blast}

The full-scale macro numerical simulations of a total of five concrete-blockwork URM walls, namely W1, W2, W3, W4 and W5 tested by Abou-Zeid et al. [19] are carried out to estimate the blast response including the displacement vs. time trend and the failure mechanisms. The masonry walls have a clear size of $0.99 \times 2.19 \mathrm{~m}$, and were constructed with the single-leaf masonry walls using standard $190 \mathrm{~mm}$ (nominal $20 \mathrm{~cm}$ ) two-cell concrete blocks bond by mortar layers with the thickness of $10 \mathrm{~mm}$. The masonry wall was built over $18.75 \mathrm{~mm}$ steel plate at the bottom and $12.5 \mathrm{~mm}$ steel plate at the top of the wall. The steel plates are considered as rigid boundaries precluding the rotation at two edges. Thus, only the masonry panel is simulated, and perfect connection is considered between the panel and the steel plates. The dimensions of the walls, test setup and instrumentations are shown in Fig. 15. Keeping the problem as pure Lagrangian formulation, the blast loads are applied as pressure profiles. This study adopts the expressions below [20-22] and information given in Table 6 to estimate the pressure profile parameters such as side-on overpressure, $P_{\text {so }}$, reflected overpressure, $P_{r}$, positive phase duration, $t_{d}$, and blast wave front velocity, $U$, to calculate the arrival time using the scaled stand-off distance, $Z=\frac{R}{W^{1 / 3}}$, and charge weight, $W$.

$$
P_{\text {so }}=\frac{1772}{Z^{3}}-\frac{114}{Z^{2}}+\frac{108}{Z}
$$

$$
\begin{aligned}
& P_{r}=2 P_{\text {so }}\left\{\frac{7 P_{o}+4 P_{s o}}{7 P_{o}+P_{\text {so }}}\right\} \\
& \frac{t_{d}}{W^{\frac{1}{3}}}=\frac{980\left(1+(Z)^{10}\right)}{\left(1+\left(\frac{Z}{0.02}\right)^{3}\right)\left(1+\left(\frac{Z}{0.74}\right)^{6}\right) \sqrt{1+\left(1+\left(\frac{Z}{6.9}\right)^{2}\right)}}
\end{aligned}
$$


$U=\sqrt{\frac{6 P_{s o}+7 P_{o}}{7 P_{o}}} \cdot a_{o}$

Here, $P_{o}$ denotes the atmospheric pressure, which is equal to 1 bar, $a_{o}$ is the ambient sound velocity and is equal to $343 \mathrm{~m} / \mathrm{sec}$ in dry air at $20{ }^{\circ} \mathrm{C}$ and $R$ is stand-off distance. The triangular shape loading protocol shown in Fig. 16 is applied on the masonry wall. Here, $P$ is the overpressure. The dynamic plasticity model is attributed to the regular fine mesh of eightnode solid elements with reduced integration to simulate the orthogonal masonry behavior with different inelastic behavior along each material axis. There are a total of 1302 elements in the numerical model of the masonry wall. Here, The $x, y, z$ axes are along the bed joint, head joint and out-of-plane directions, respectively. The material properties of mortar and masonry determined from the experiments [19] served as quasi-static reference mechanical characteristics for the calibration of input parameters, see Table 7 and Table 8.

\section{Comparison of results}

The numerical predictions of the out-of-plane behavior of masonry walls subjected to large detonations include the displacement vs. time trend and the post-test observed crack patterns. Regarding the test data, the masonry panel behaves as a plate constrained on top and bottom edges and the maximum displacement is obtained at mid-height. In numerical simulations, the maximum displacement is recorded at the points placed at the top, three quarter height and center of the panel. The displacement at top of the wall was taken equal to zero due to the defined end conditions as discussed before. Fig. 17 shows the comparative maximum displacements of the upper segment of the wall captured at given points. In all cases except W1, no significant bulging is shown for the arched walls at three quarter-height, indicating a rigid-body rocking. Comparing the numerical results with the test data for each wall, it is 
noted that the maximum displacements are well predicted. Errors are noted in prediction of the reference data at specified points of each wall. However, keeping the stand-off distance constant and increasing the charge weight result in growing the errors in prediction of the test results. Ignoring the negative phase of applied pressure protocol, initiation of the crack formation followed by escalation of the cracks can partly justify the differences.

The maximum principal plastic strain is involved to indicate the crack distribution. Fig. 18 shows the numerically simulated response of the wall W4 as the representative of masonry walls in terms of the post-test back face crack distribution, deformed mesh at maximum deflection and post-test observed crack patterns in the test. Regarding the predictions, there is a concentration of horizontal fracture lines at mid-height along the entire length of the wall. The entire wall is broken with one horizontal line and is divided into two parts in a typical three-hinged mechanism. As noted, the results concerning the crack patterns are replicated close to the test data.

\section{$5 \quad$ Parametric studies}

A parametric study is conducted to estimate the influence of changes in the most dominant parameters on the impact response of the masonry walls, by comparing the out of plane displacement vs. time evolution and the crack formation with the reference response. The wall URP1, used for validation, is considered in this section.

\subsection{Influence of tensile strength}

As mentioned before, masonry is constructed with individual units bond by horizontal mortar layers. Consequently, besides the scatter usually found in masonry properties, the masonry tensile strength varies significantly along the different material axes. Hence, the influence of the tensile strengths at different directions on impact behavior and damage level of the masonry parapets is evaluated in this parametric study. Each subsequent graph gives the 
displacement vs. time evolution of the walls with different tensile strengths along the material axes, considering an extreme range of values. As shown in Fig. 19 to Fig. 21, increasing the tensile strength at each direction reduces the maximum displacement; however, the influence of tensile strength is much more significant in vertical and out of plane directions, but lower in horizontal direction. Comparing the crack distribution of the wall at horizontal direction, it can be inferred that tensile strength changes does not obviously affect the crack patterns, see Fig. 22. As noted in Fig. 23 and Fig. 24, the reduction of tensile strength in vertical or out of plane direction does not effectively change the governing failure mechanisms, but rises the magnitude of maximum principal plastic strain at integration points close to the centerline at both sides, which indicates the intensification of localized cracks in this zone.

\subsection{Influence of wall thickness}

Three different types of wall thicknesses of $200 \mathrm{~mm}, 250 \mathrm{~mm}$, and $300 \mathrm{~mm}$ are applied to evaluate the effect of wall thickness. The reference masonry material properties are adopted in the three walls. It is noted that the wall with the thickness of $200 \mathrm{~mm}$ has the maximum out of plane deflection. As expected, the growth of the wall thickness, almost 1.5 times, causes an evident reduction of up to 2.7 times in maximum displacement of the wall, see Fig. 25. This in opposition with a quasi-static elastic calculation, where this deformation would be proportional to the bending stiffness (in this case, this would be a maximum difference $1.5^{3}=$ 3.4). Fig. 26 shows that decreasing the wall thickness, and thus lowering the out of plane bending stiffness of the wall results in growth of the damages over the entire length of the wall.

\subsection{Influence of strain rate dependency}

One aspect that is of interest is to compare a model with strain rate dependency, labeled A, (i.e. making each integration point to have a different strength, given by its own strain rate and velocity) with a model, where the properties are assumed identical in all integration 
points, and equal to the properties of the integration point situated at mid height, labeled B. The results of the analysis, shown in Fig. 27 to Fig. 28 indicate that by adopting the same properties in all integration points the out of plane displacement vs. time trend is slightly reduced, but the response is very similar. Additionally, the changes on fracture line distribution are imperceptible. If higher strain rates occur, by applying double of the original impulse, the changes between the analyses, including the displacement vs. time response, and the failure mode, are more intensified, see Fig. 29 and Fig. 30. This demonstrates that a simplified assumption, not including a proper point-wise dependency of material properties according to the actual strain rate, is not recommended.

\section{Conclusion}

The present study introduces a novel strain rate dependent anisotropic continuum model for the simulation of masonry structures. The composite plasticity model is implemented as a user-defined subroutine in the finite element code ABAQUS, in the context of 3D solid elements to simulate the masonry behavior. The adequacy of the material model to replicate measured dynamic increase factors measures experimentally is demonstrated by applying various uniaxial loading conditions. The numerical simulation of high strain rate responses of two full scale masonry parapets and five arching unreinforced concrete masonry walls is carried out to evaluate the performance and validity of the proposed model and the results are compared with test reference values. The numerical simulations accounting for the maximum deflection and crack patterns over the entire length of the wall are well replicated when compared with test data. Moreover, the structural responses including the displacement vs. time and strain rate vs. time in specific points and time history of strain rate at different stages, namely cracking, reusable, non-reusable, and peak are evaluated to study the performance of URP1 to impact. A parametric study is also performed to study the 
effectiveness of the most likely main properties on impact response of the walls. As noted, the influence of tensile strength on maximum deflection and crack patterns of the masonry wall is much more significant in vertical and out of plane directions, but less in horizontal direction. The reduction of tensile strength in vertical or out of plane direction leads to a localized failure close to the impact zone. As expected, increasing the wall thickness decreases the maximum deflection and damage, but the changes obtained for fast impact are significantly different from the changes in stiffness obtained in a linear elastic calculation. A final case is the evaluation of the influence of strain rate dependency. It is concluded that considering the same properties in all integration points causes a slight decrease in displacement vs. time trend and imperceptible changes on crack distribution for low strain rates. At higher strain rates, the changes are significant and the use of a proper point-wise dependency of material properties according to the actual strain rate, as it is done here, is recommended.

\section{Acknowledgement}

This work was performed under Project CH-SECURE, with reference PTDC/ECM/120118/2010, funded by the Portuguese Foundation of Science and Technology - FCT. The authors acknowledge the support. The first author also acknowledges the support for the Strategic Planning of the School of Engineering from University of Minho.

\section{References}

[1] Baylot JT, Bullock B, Slawson TR, Woodson SC. Blast response of lightly attached concrete masonry unit walls. Journal of Structural Engineering. 2005;131:1186-93.

[2] Dennis ST, Baylot JT, Woodson SC. Response of 1/4-scale concrete masonry unit (CMU) walls to blast. Journal of Engineering Mechanics. 2002;128:134-42.

[3] Eamon CD, Baylot JT, O'Daniel JL. Modeling concrete masonry walls subjected to explosive loads. Journal of Engineering Mechanics. 2004;130:1098-106.

[4] Gilbert M, Hobbs B, Molyneaux T. The performance of unreinforced masonry walls subjected to low-velocity impacts: experiments. International Journal of Impact Engineering. 2002;27:231-51. 
[5] Myers JJ, Belarbi A, El-Domiaty KA. Blast resistance of FRP retrofitted un-reinforced masonry (URM) walls with and without arching action. The Masonry Society Journal. 2004;22:9-26.

[6] Davidson JS, Porter JR, Dinan RJ, Hammons MI, Connell JD. Explosive testing of polymer retrofit masonry walls. Journal of Performance of Constructed Facilities. 2004;18:100-6.

[7] Lourenço PB. Computational strategies for masonry structures [PhD Dissertation]. Delft, The Netherlands: Delft University of Technology; 1996.

[8] Milani G, Lourenço PB. Blast analysis of enclosure masonry walls using homogenization approaches. International Journal for Multiscale Computational Engineering. 2009;7.

[9] Eamon CD. Reliability of concrete masonry unit walls subjected to explosive loads. Journal of Structural Engineering. 2007;133:935-44.

[10] Wei X, Stewart MG. Model validation and parametric study on the blast response of unreinforced brick masonry walls. International Journal of Impact Engineering. 2010;37:1150-9.

[11] Milani G, Lourenço PB, Tralli A. Homogenized rigid-plastic model for masonry walls subjected to impact. International Journal of Solids and Structures. 2009;46:4133-49.

[12] Feenstra PH. Computational aspects of biaxial stress in plain and reinforced concrete [PhD Dissertation]. Delft, The Netherlands: Delft University of Technology; 1993.

[13] Rots JG. Computational modeling of concrete fracture [PhD Dissertation]. Delft, The Netherlands: Delft University of Technology; 1988.

[14] Rafsanjani SH. High strain rate constitutive modeling for historical structures subjected to blast loading [PhD Dissertation]. Guimaraes, Portugal: University of Minho; 2015.

[15] Wei X, Hao H. Numerical derivation of homogenized dynamic masonry material properties with strain rate effects. International Journal of Impact Engineering. 2009;36:52236.

[16] Pereira JM. Security Evaluation and Design of Structures Subjected to Blast Loading [PhD Dissertation]. Guimaraes, Portugal: University of Minho; 2014.

[17] Rafsanjani SH, Lourenço PB, Peixinho N. Dynamic interface model for masonry walls subjected to high strain rate out-of-plane loads. International Journal of Impact Engineering. 2015;76:28-37.

[18] UFC. Structures to resist the effects of accidental explosions. Department of Defense, Unified Facilities Criteria 3-340-02, Washington, DC, USA 2008.

[19] Abou-Zeid BM, El-Dakhakhni WW, Razaqpur AG, Foo S. Response of arching unreinforced concrete masonry walls to blast loading. Journal of Structural Engineering. 2010;137:1205-14.

[20] Mills CA. The design of concrete structure to resist explosions and weapon effects. In Proc of the 1st International Conference on concrete for hazard protections, Edinburgh, UK1987. p. 61-73.

[21] Bangash M, Bangash T. Explosion-resistant buildings: design, analysis, and case studies: Springer; 2006.

[22] Kinney GF, Graham KJ. Explosive shocks in air. Berlin and New York, SpringerVerlag, 1985, 282 p. 1985;1. 


\section{List of figures}

Fig. 1. Proposed composite yield surface with different strength values for tension and

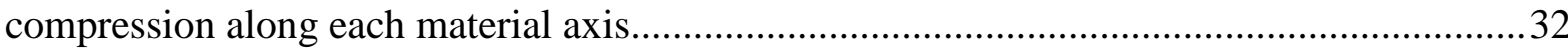

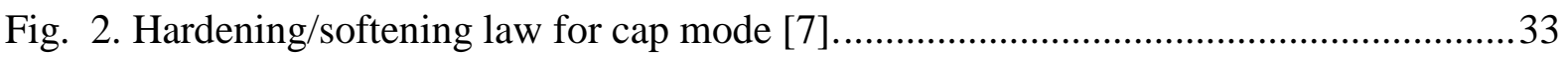

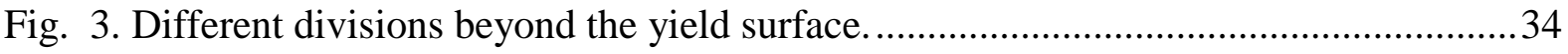

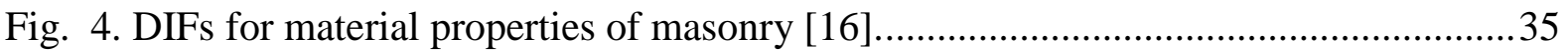

Fig. 5. Orthotropic material behavior of masonry at different strain rates: (a) simple numerical model; uniaxial tensile behavior in (b) x direction (c) y direction (d) z direction; uniaxial compressive behavior in (e) $\mathrm{x}$ direction (f) y direction (g) $\mathrm{z}$ direction. 
Fig. 6. Geometry of masonry parapet subjected to low velocity impact [4].........................37

Fig. 7. Typology of dynamic load applied to: (a) URP1; (b) URP2 ......................................38

Fig. 8. Displacement vs. time response of the wall: (a) URP1; (b) URP2............................39

Fig. 9. Influence of dynamic properties in the response of URP1 ....................................... 40

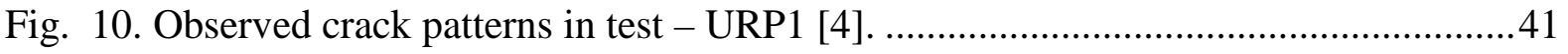

Fig. 11. Observed crack patterns in test - URP2 [4].....................................................42

Fig. 12. Results of the analysis of URP1 at ultimate deflection: (a) deformed mesh; maximum principal plastic strain at the (b) front and (c) back face....................................43

Fig. 13. Results of the analysis of URP2 at ultimate deflection: (a) deformed mesh; maximum principal plastic strain at the (b) front and (c) back face

Fig. 14. Results of the analysis of URP1 at specified points: (a) location of the points; (b) displacement vs. time response; (c) strain rate vs. time response; time history of strain rate (d) cracking, (e) reusable, (f) non-reusable and (g) peak stage. ...................................................45

Fig. 15. Test setup and instrumentations: (a) elevation; (b) interior instrumentations [19]. ..46

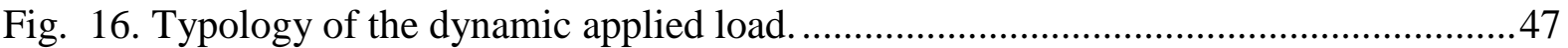

Fig. 17. Comparative maximum mid-height displacements of walls W1-W5 [19]...............48

Fig. 18. Post-blast observations of W4 after shot: simulation (a) back face maximum principal plastic strain; (b) deformed mesh at maximum deflection; test (c) crack patterns [19].

Fig. 19. Displacement vs. time diagram of URP1with different tensile strengths in horizontal direction. .50

Fig. 20. Displacement vs. time diagram of URP1with different tensile strengths in vertical direction.

Fig. 21. Displacement vs. time diagram of URP1with different tensile strengths in out of plane direction.

Fig. 22. Crack patterns of URP1 at ultimate deflection with different tensile strengths in horizontal direction: $\mathrm{f}_{\mathrm{tx}}=0.0065 \mathrm{MPa}(\mathrm{a})$ front and (b) back face; $\mathrm{f}_{\mathrm{tx}}=0.026 \mathrm{MPa}$ (c) front and (d) back face; $\mathrm{ftx}_{\mathrm{tx}}=0.13 \mathrm{MPa}(\mathrm{e})$ front and (f) back face; $\mathrm{f}_{\mathrm{tx}}=0.65 \mathrm{MPa}(\mathrm{g})$ front and (h) back face.

Fig. 23. Crack patterns of URP1 at ultimate deflection with different tensile strengths in vertical direction: $\mathrm{f}_{\mathrm{ty}}=0.00215 \mathrm{MPa}(\mathrm{a})$ front and (b) back face; $\mathrm{f}_{\mathrm{ty}}=0.0086 \mathrm{MPa}$ (c) front and (d) back face; $\mathrm{f}_{\mathrm{ty}}=0.043 \mathrm{MPa}(\mathrm{e})$ front and (f) back face; $\mathrm{f}_{\mathrm{ty}}=0.215 \mathrm{MPa}(\mathrm{g})$ front and (h) back face.

Fig. 24. Crack patterns of URP1 at ultimate deflection with different tensile strengths in out of plane direction: $\mathrm{f}_{\mathrm{tz}}=0.0615 \mathrm{MPa}(\mathrm{a})$ front and (b) back face; $\mathrm{f}_{\mathrm{tz}}=0.246 \mathrm{MPa}$ (c) front and (d) back face; $\mathrm{f}_{\mathrm{tz}}=1.23 \mathrm{MPa}(\mathrm{e})$ front and (f) back face; $\mathrm{f}_{\mathrm{tz}}=6.15 \mathrm{MPa}$ (g) front and (h) back face.

Fig. 25. Displacement vs. time responses of the wall URP1 with three wall thicknesses: (a) $\mathrm{t}=200 \mathrm{~mm}$; (b) $\mathrm{t}=250 \mathrm{~mm}$; (c) $\mathrm{t}=300 \mathrm{~mm}$.

Fig. 26. Crack patterns of URP1 at ultimate deflection with three different wall thicknesses: $\mathrm{t}=200 \mathrm{~mm}$ (a) front and (b) back face; $\mathrm{t}=250 \mathrm{~mm}$ (c) front and (d) back face; t=300 mm (e) front and (f) back face.

Fig. 27. Displacement vs. time responses of the wall URP1 for two different approaches: (a) different properties in integration points; (b) identical properties in integration points. 
Fig. 28. Crack patterns of URP1 at ultimate deflection for two different approaches: different properties in integration points (a) front and (b) back face; identical properties in integration points (c) front and (d) back face.

Fig. 29. Displacement vs. time responses of the wall URP1 for two different approaches against double applied impulse: (a) different properties in integration points; (b) identical properties in integration points.

Fig. 30. Crack patterns of URP1 at ultimate deflection for two different approaches against different applied impulse: different properties in integration points (a) front and (b) back face; identical properties in integration points (c) front and (d) back face.

\section{List of tables}

Table 1. Elastic material properties for masonry and corresponding DIFs [17] .62

Table 2. Inelastic material properties for masonry and corresponding DIFs [17]

Table 3. Elastic material properties for masonry parapets [17]

Table 4. Inelastic material properties for masonry parapets [17] .........................................65

Table 5. Masonry damage criteria (UFC-3-340-02, 2008) [18] ............................................66

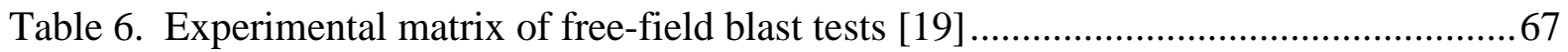

Table 7. Elastic material properties for masonry walls [19] ................................................68

Table 8. Inelastic material properties for masonry walls [19] ............................................69 


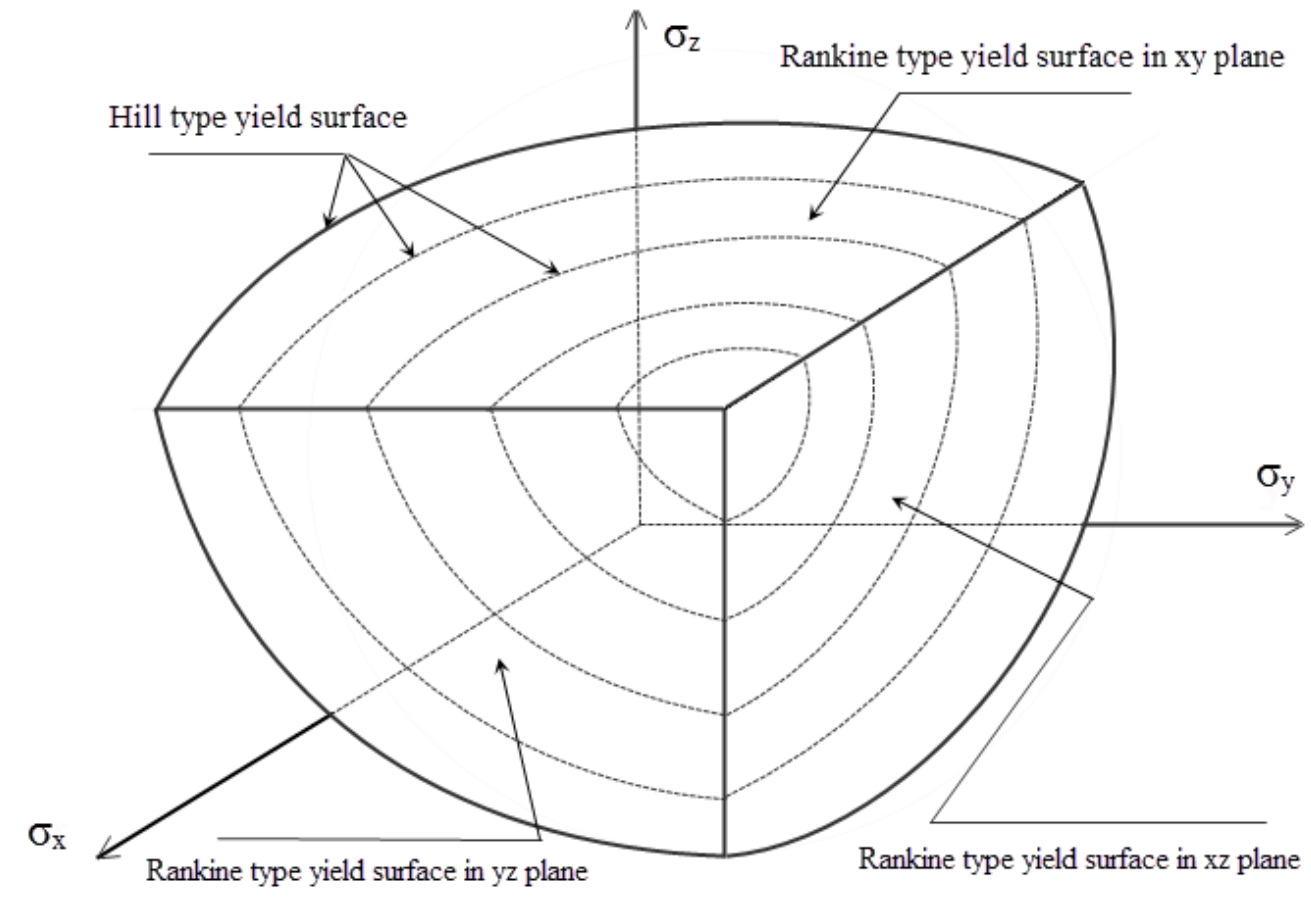

Fig. 1. Proposed composite yield surface with different strength values for tension and compression along each material axis. 


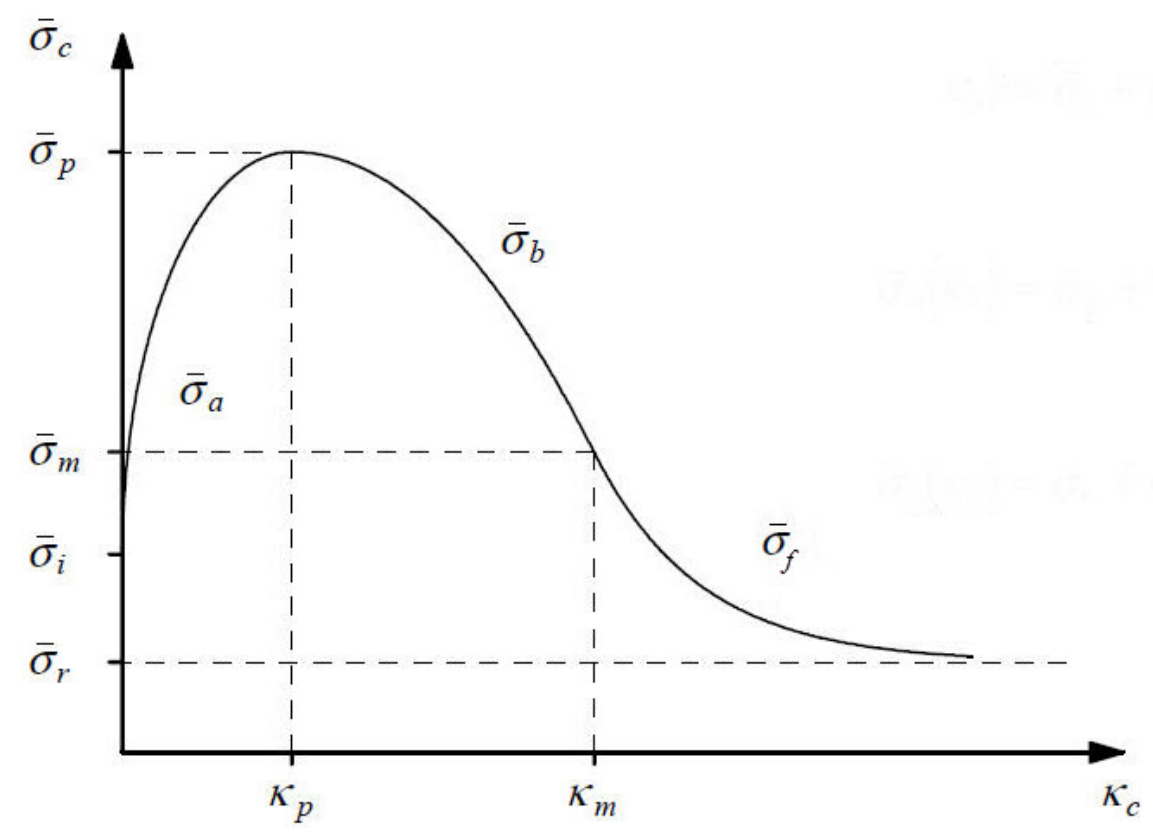

Fig. 2. Hardening/softening law for cap mode [7]. 


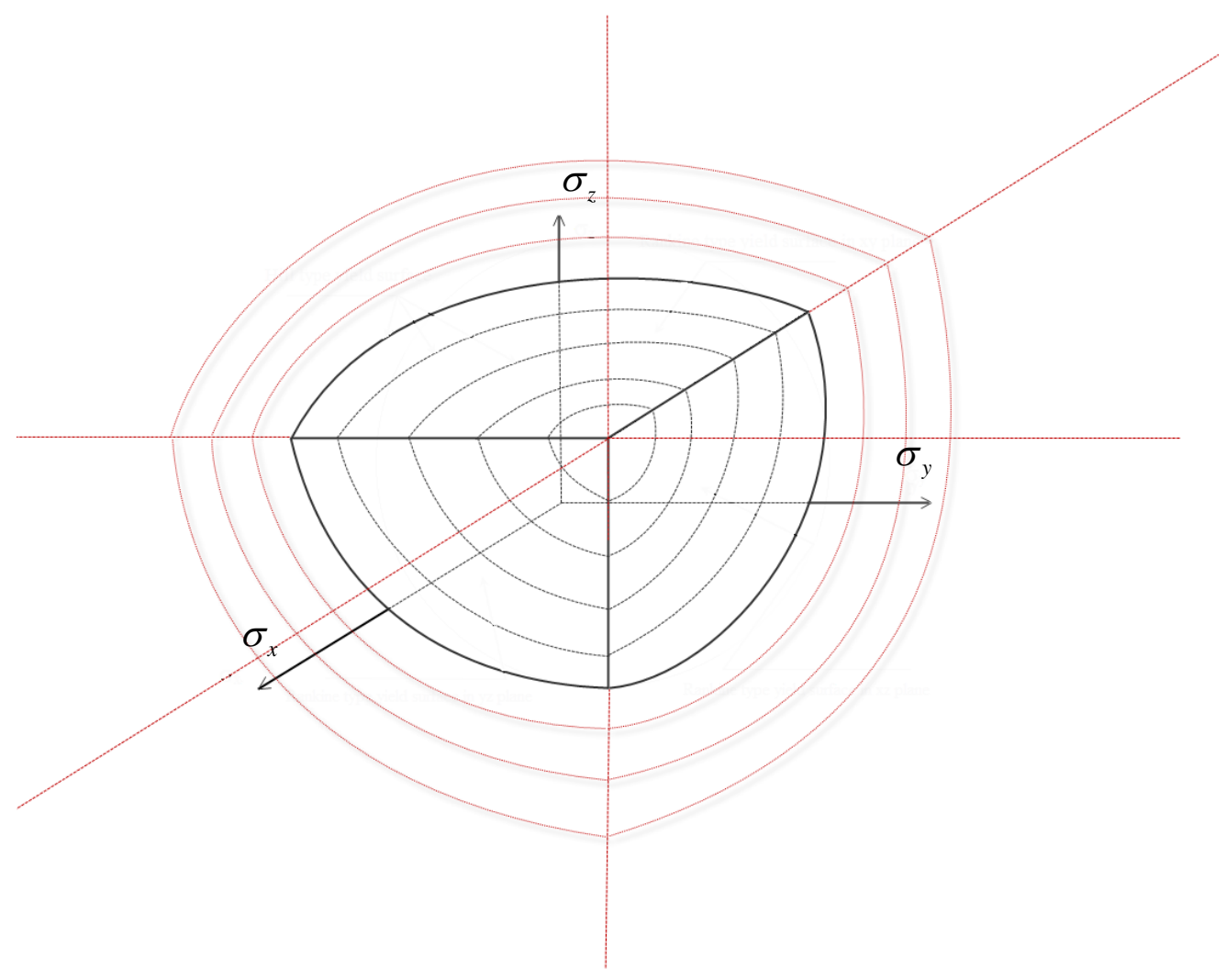

Fig. 3. Different divisions beyond the yield surface. 


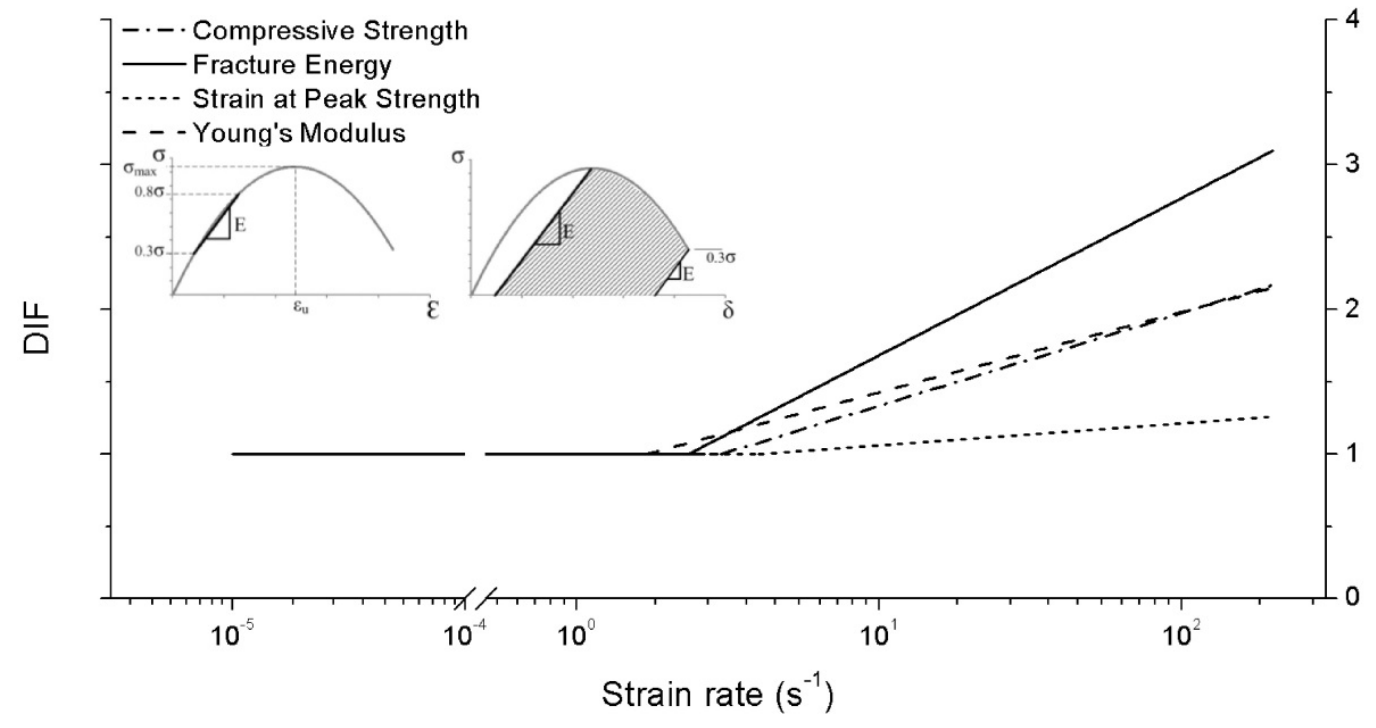

Fig. 4. DIFs for material properties of masonry [16]. 


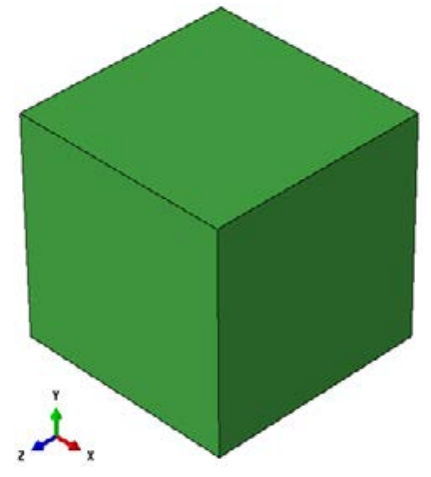

(a)

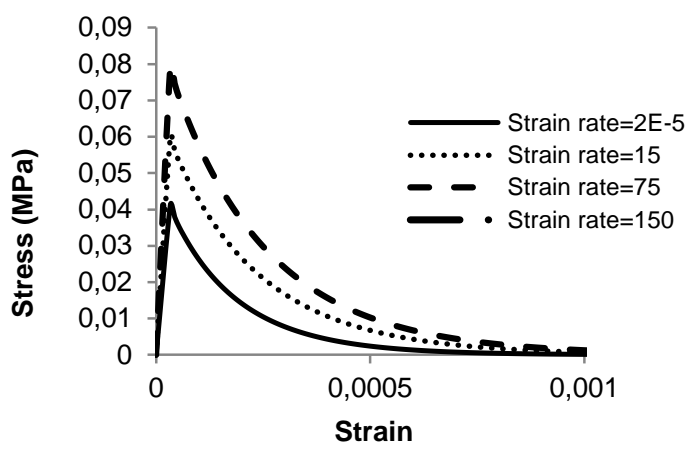

(c)

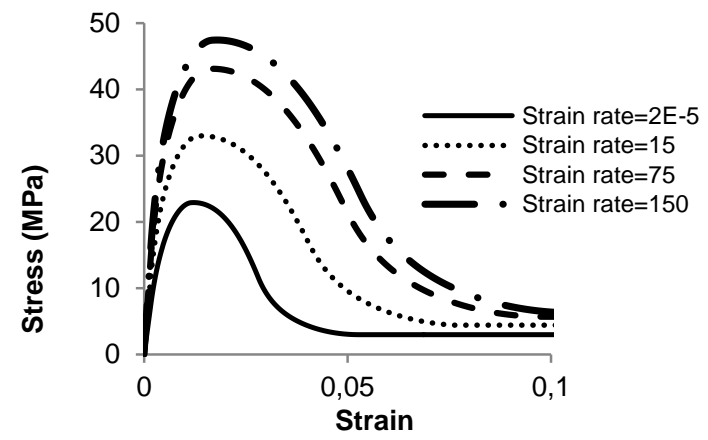

(e)

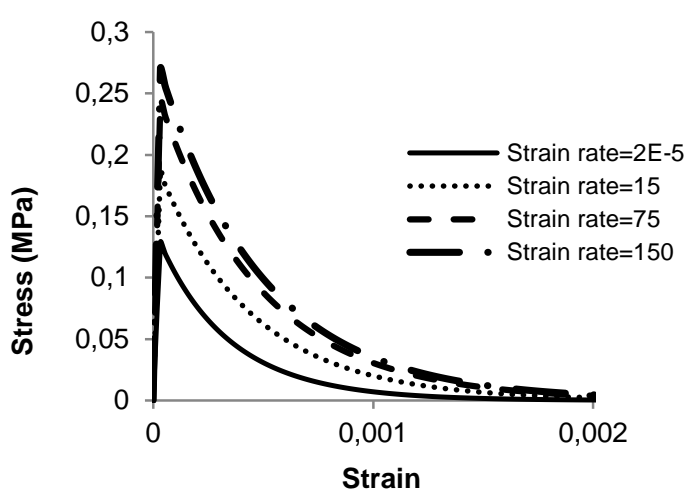

(b)

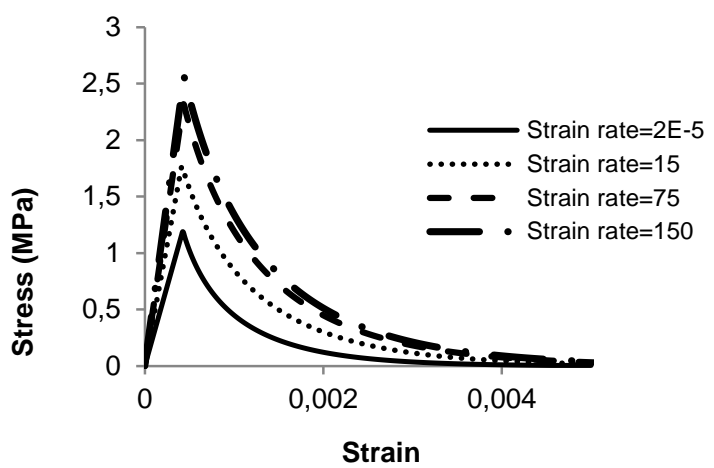

$(d)$

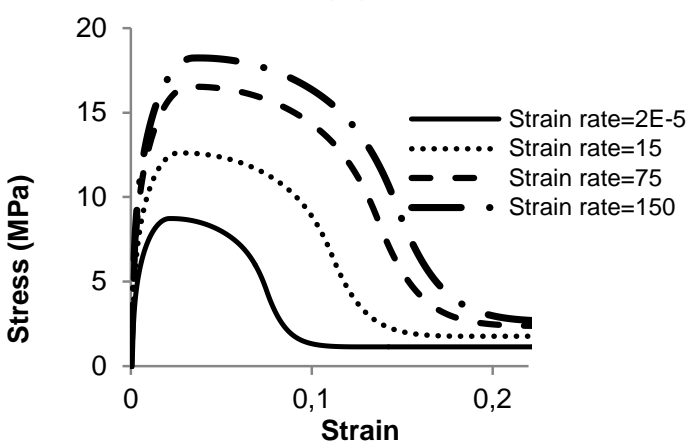

$(f)$

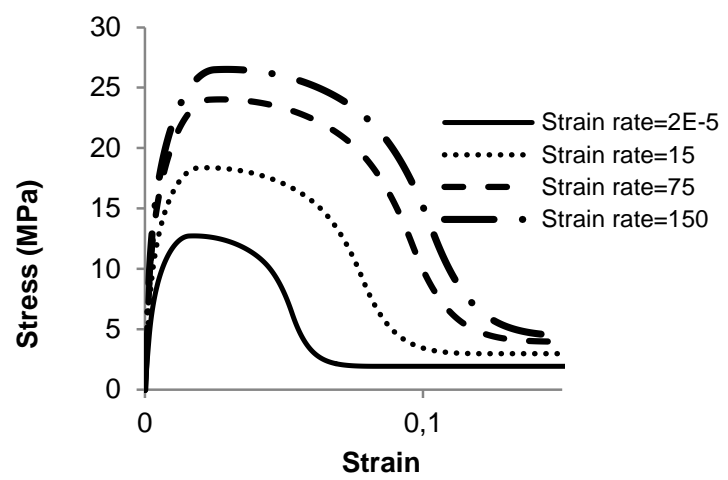

$(g)$

Fig. 5. Orthotropic material behavior of masonry at different strain rates: (a) simple numerical model; uniaxial tensile behavior in (b) x direction (c) y direction (d) z direction; uniaxial compressive behavior in (e) $\mathrm{x}$ direction (f) y direction (g) z direction. 


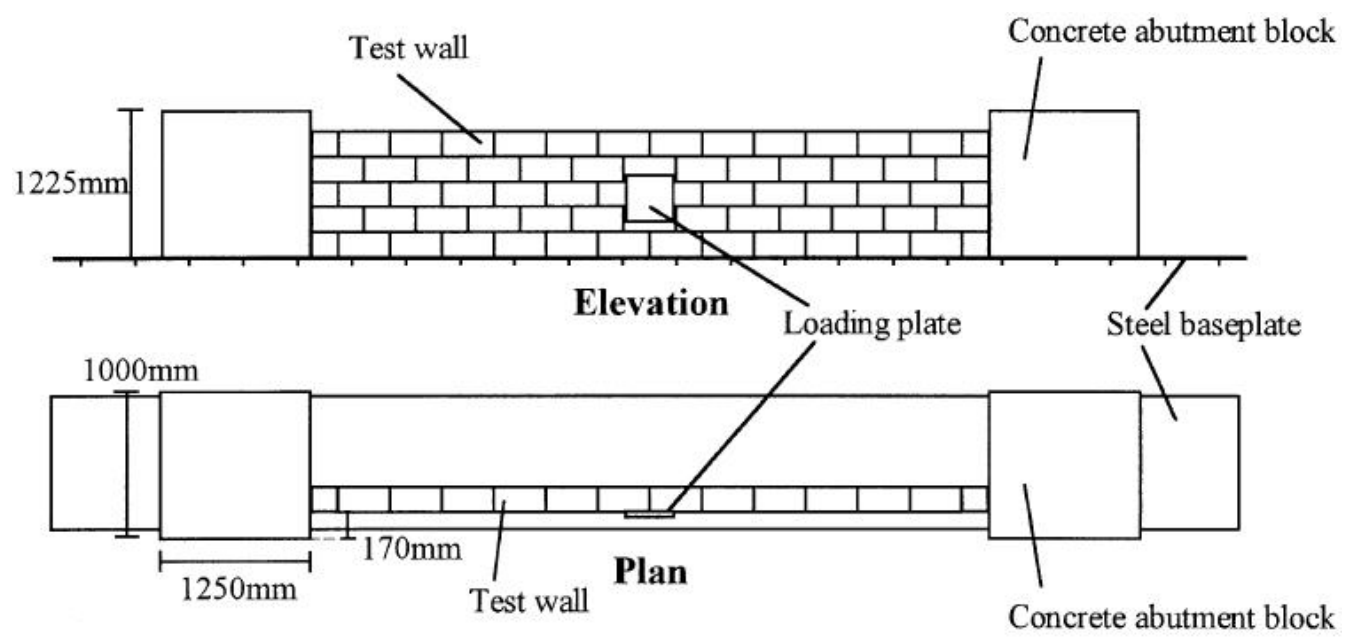

Fig. 6. Geometry of masonry parapet subjected to low velocity impact [4]. 


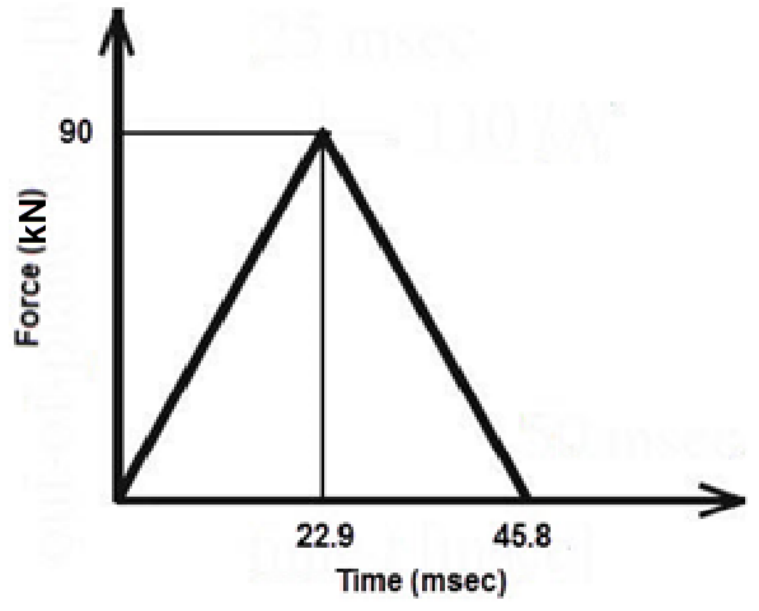

(a)

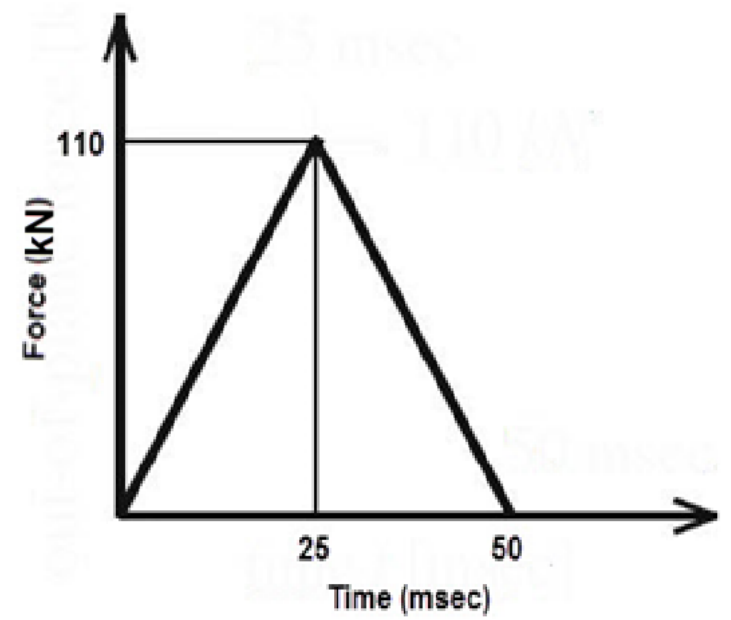

(b)

Fig. 7. Typology of dynamic load applied to: (a) URP1; (b) URP2. 


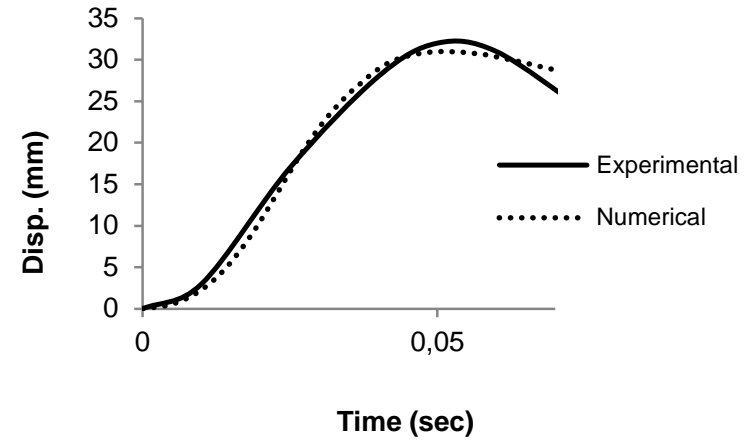

(a)

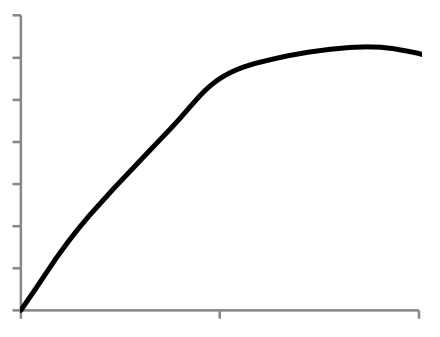

(b)

Fig. 8. Displacement vs. time response of the wall: (a) URP1; (b) URP2. 


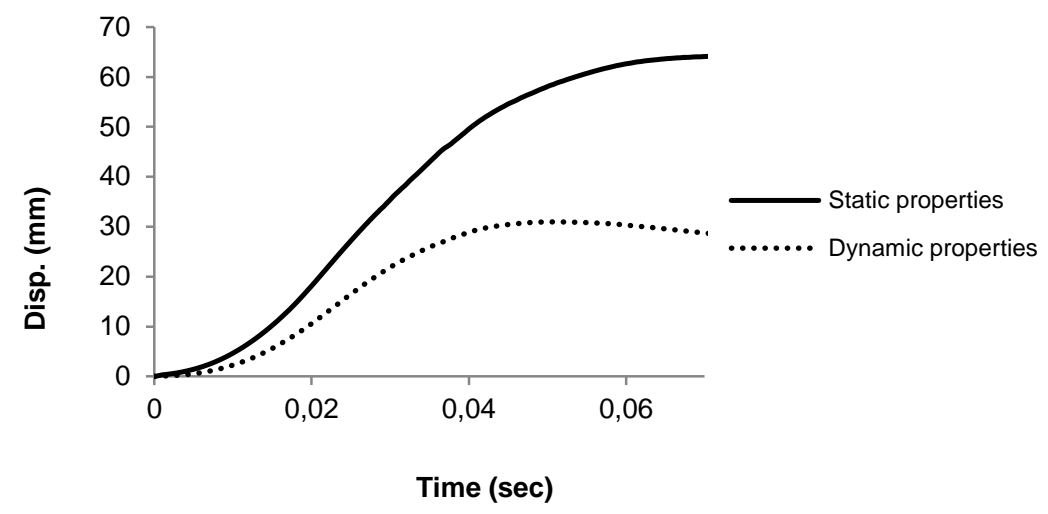

Fig. 9. Influence of dynamic properties in the response of URP1. 


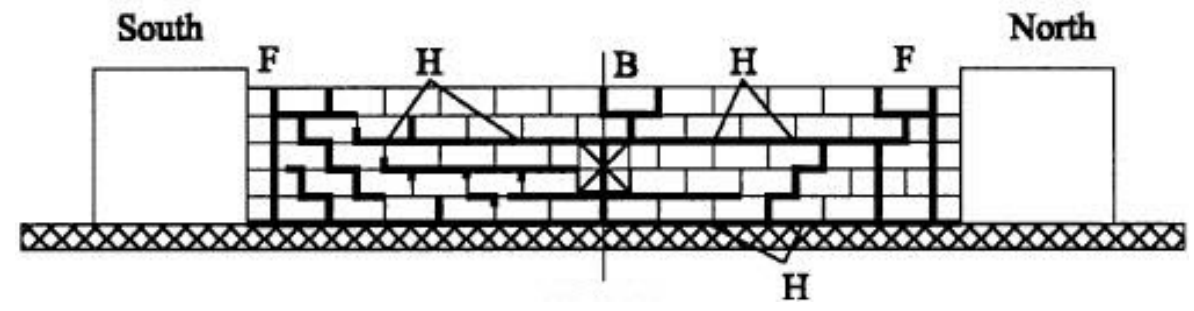

Fig. 10. Observed crack patterns in test - URP1 [4]. 


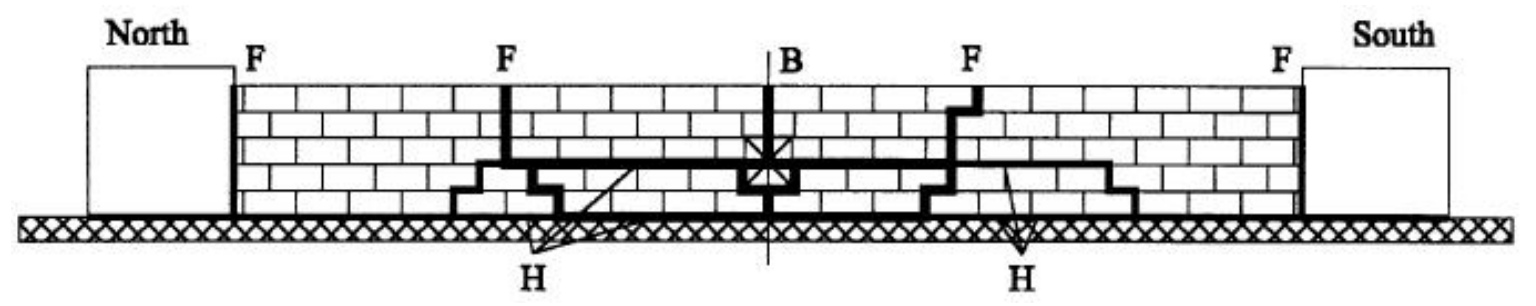

Fig. 11. Observed crack patterns in test - URP2 [4]. 


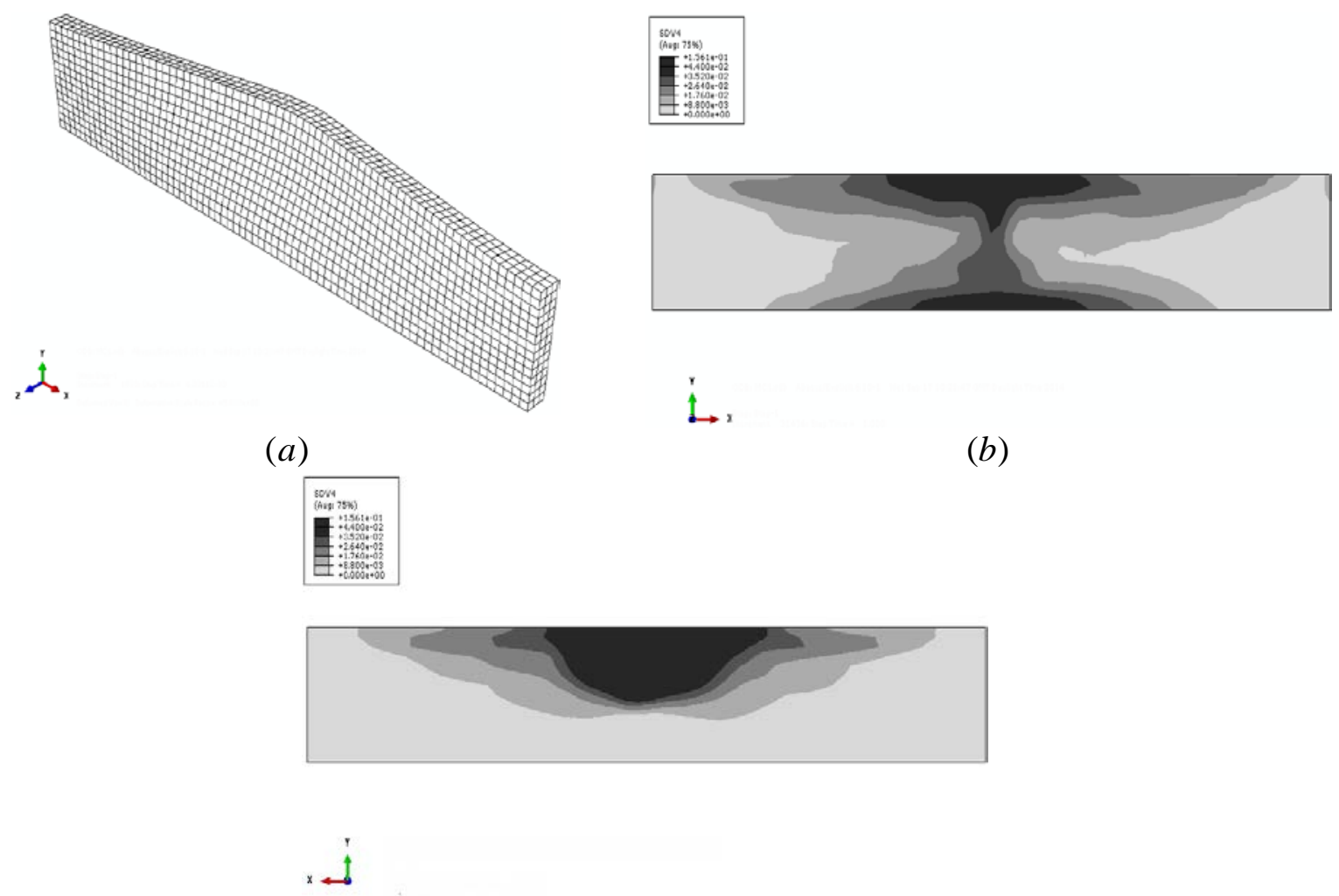

(c)

Fig. 12. Results of the analysis of URP1 at ultimate deflection: (a) deformed mesh; maximum principal plastic strain at the (b) front and (c) back face. 


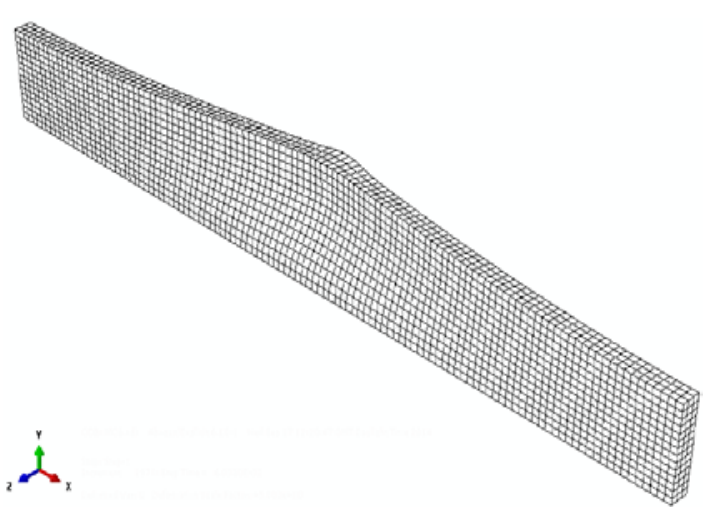

(a)

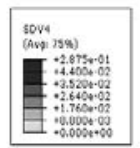

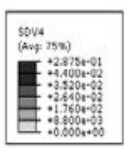

$\stackrel{\leftrightarrow}{\rightarrow} x$

(b)

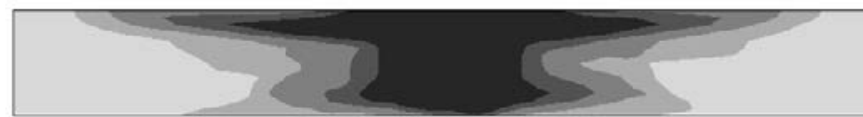

$\times \stackrel{\sim}{\sim}$

(c)

Fig. 13. Results of the analysis of URP2 at ultimate deflection: (a) deformed mesh; maximum principal plastic strain at the (b) front and (c) back face. 

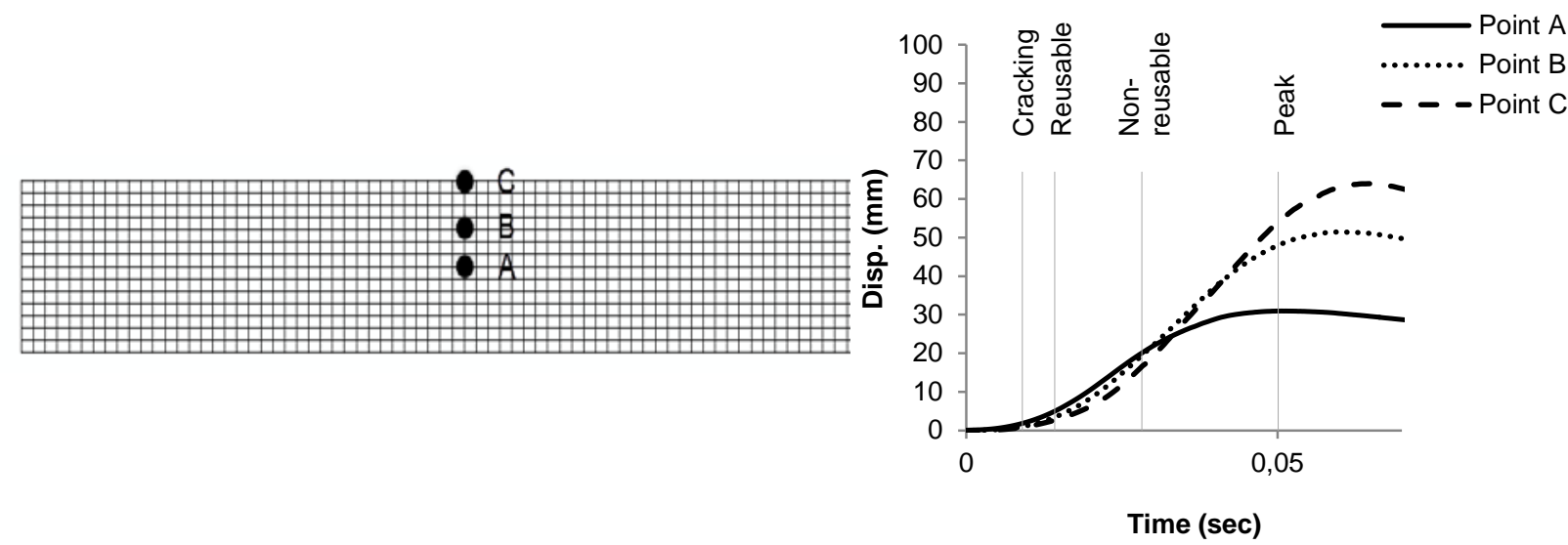

(a)

(b)

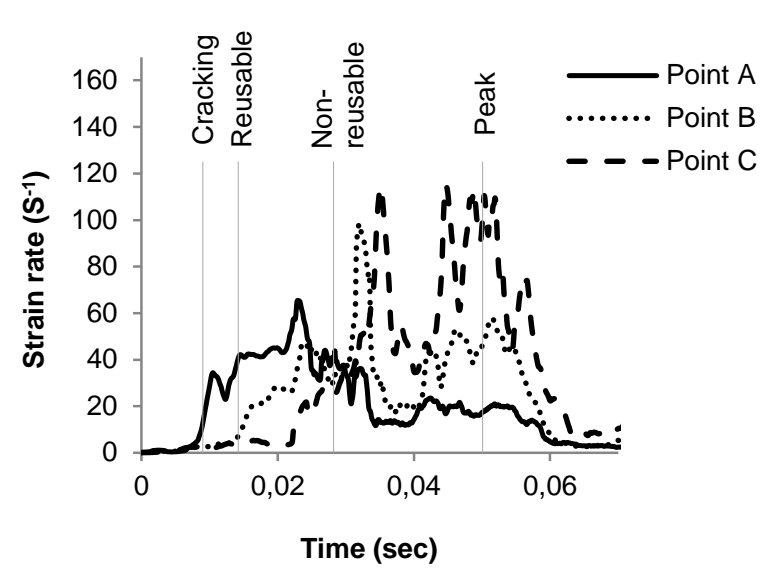

(c)
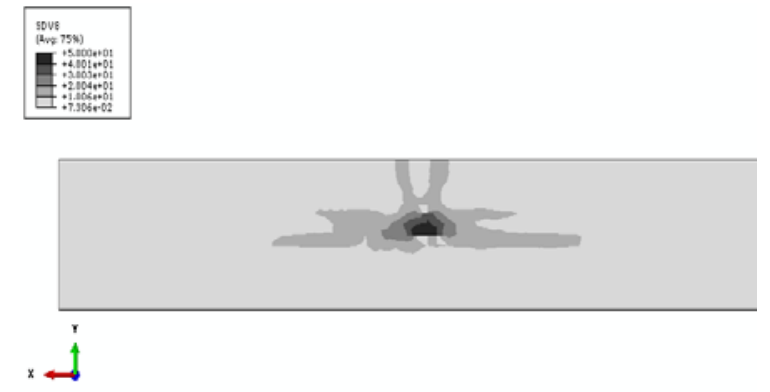

(d)
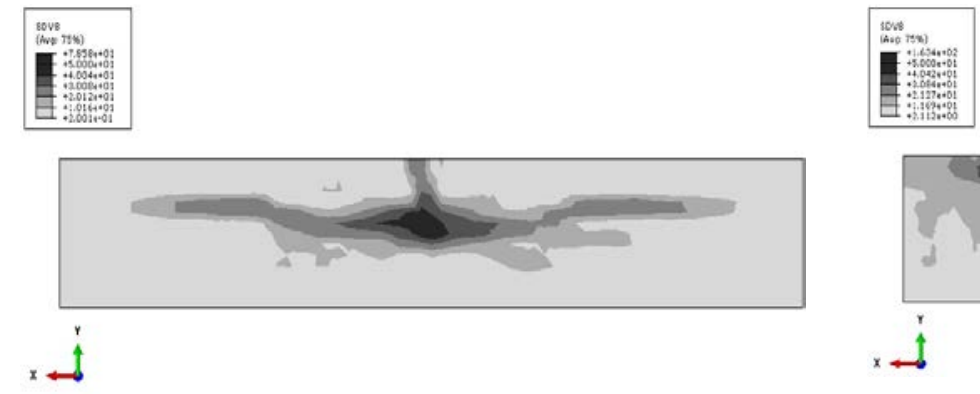

(e)

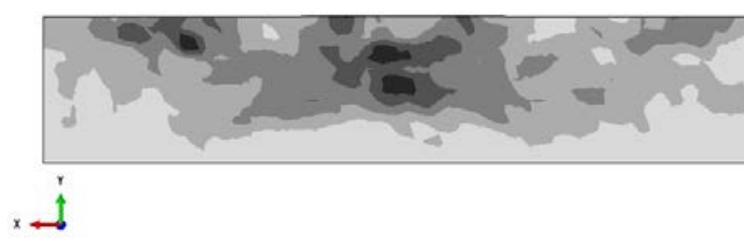

$(f)$
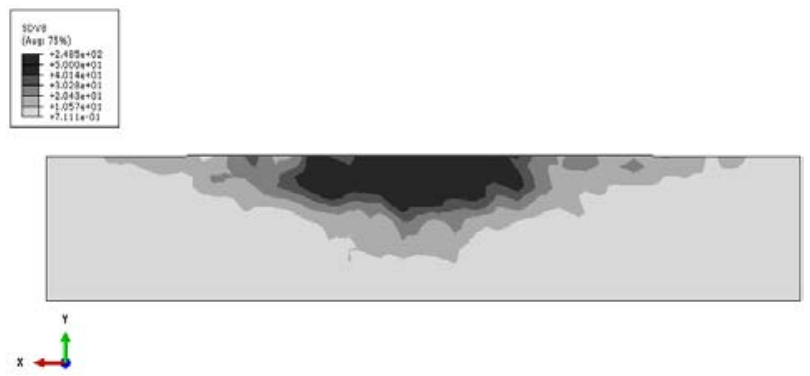

$(g)$

Fig. 14. Results of the analysis of URP1 at specified points: (a) location of the points; (b) displacement vs. time response; (c) strain rate vs. time response; time history of strain rate (d) cracking, (e) reusable, (f) non-reusable and (g) peak stage. 


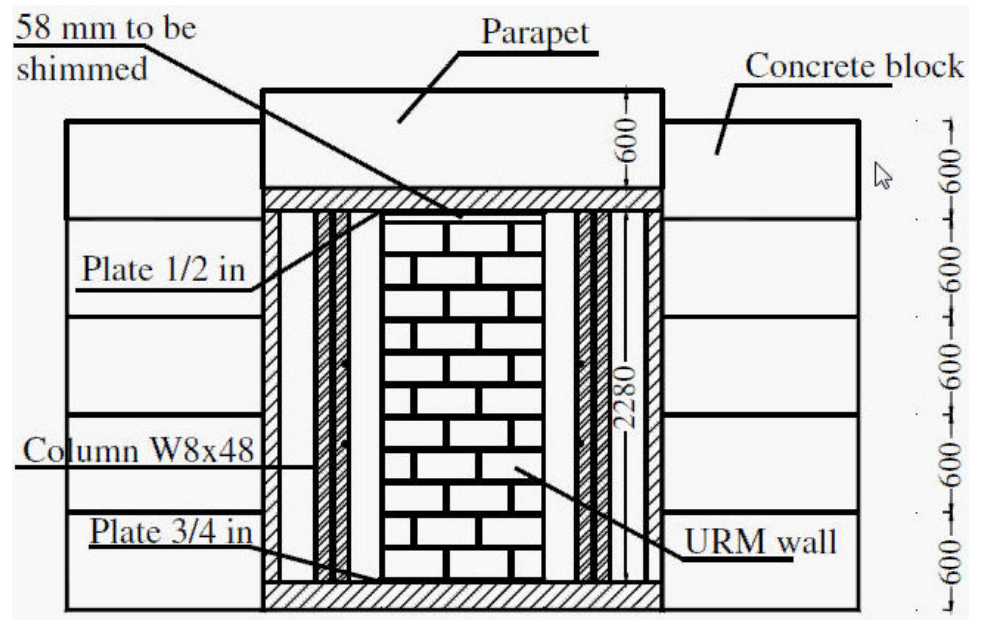

$\leftarrow 625 \perp-190 \longrightarrow-625-$

All Dimensions are in $\mathrm{mm}$

(a)

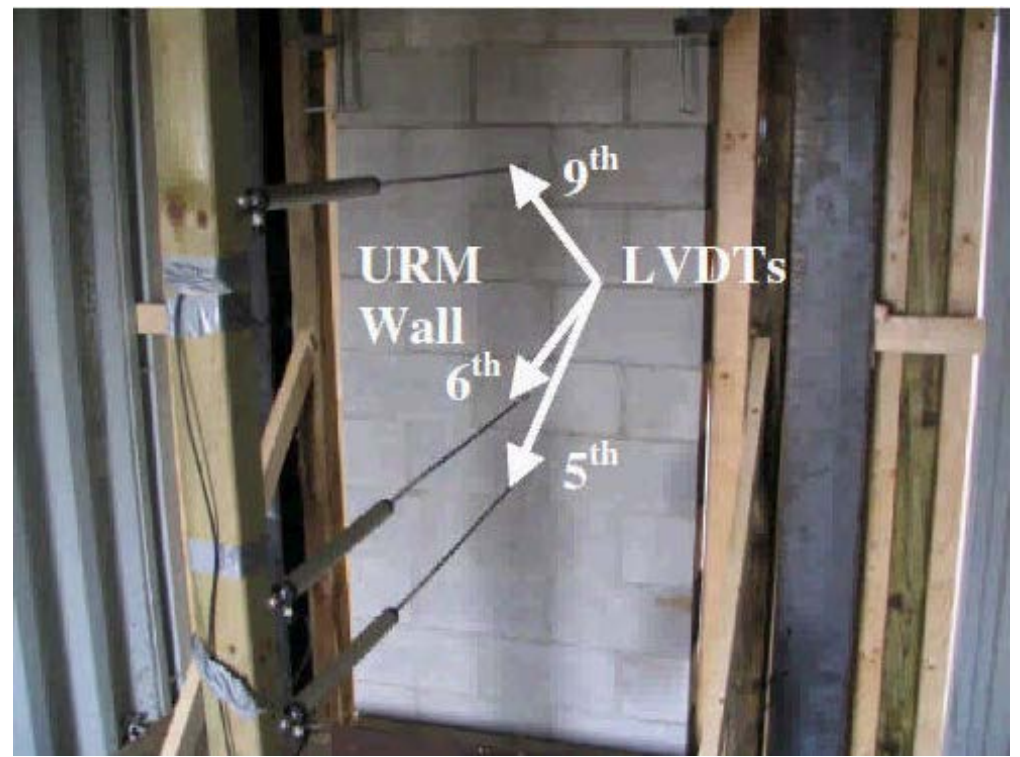

(b)

Fig. 15. Test setup and instrumentations: (a) elevation; (b) interior instrumentations [19]. 


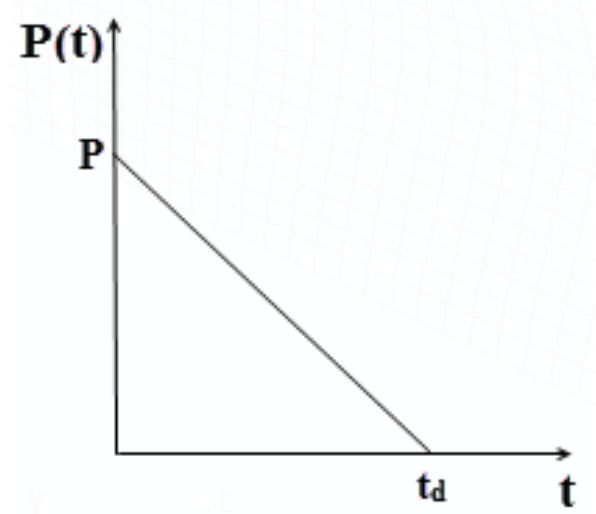

Fig. 16. Typology of the dynamic applied load. 


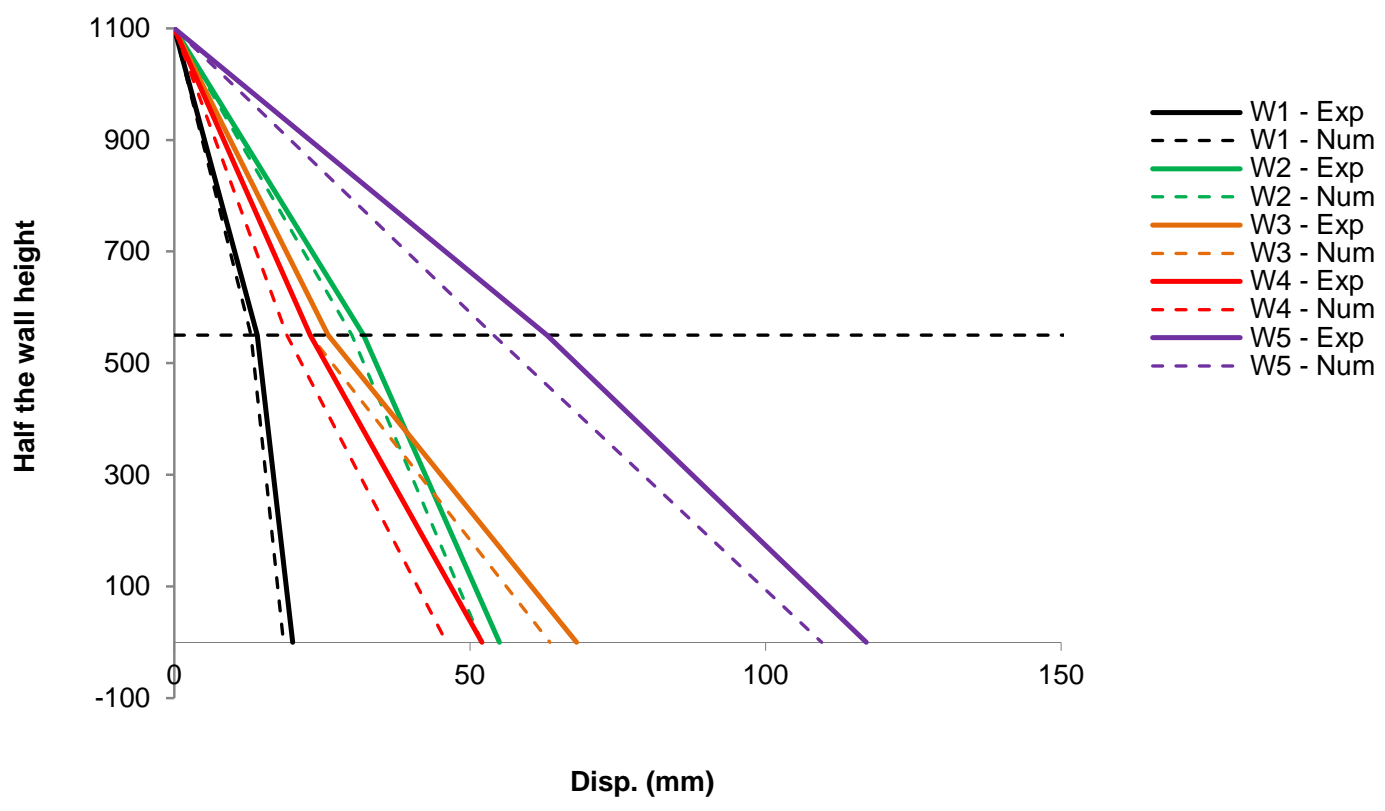

Fig. 17. Comparative maximum mid-height displacements of walls W1-W5 [19]. 


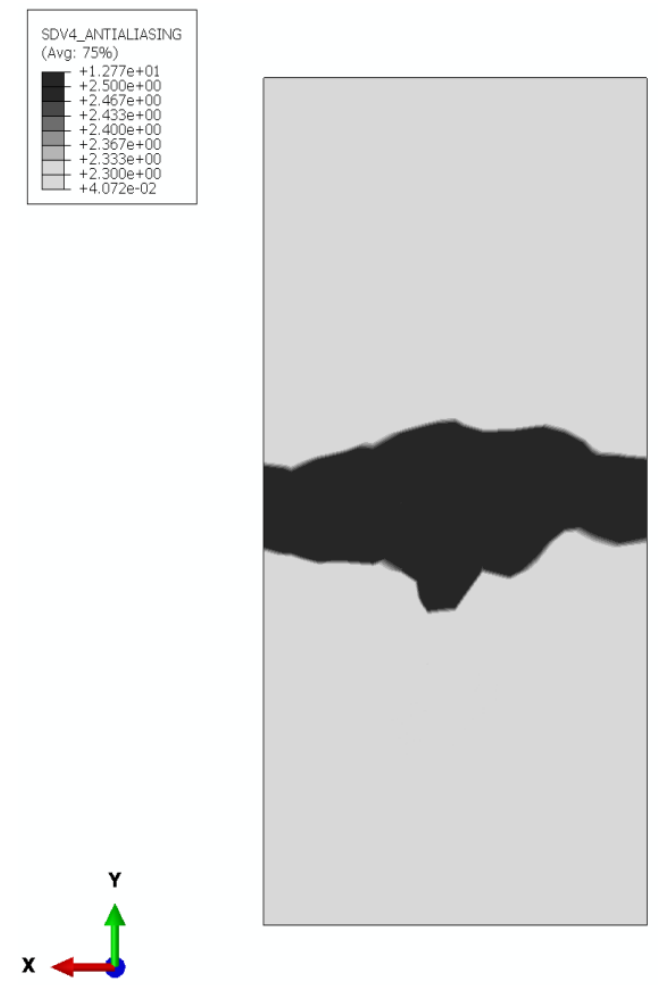

(a)

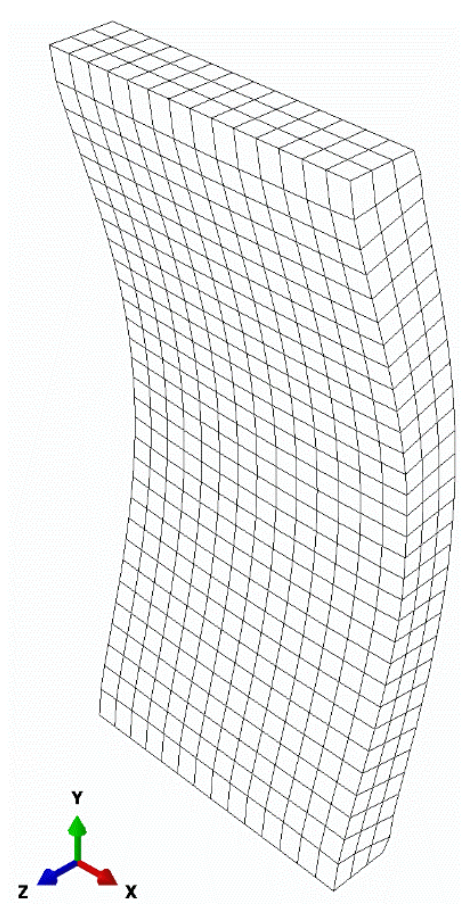

(b)

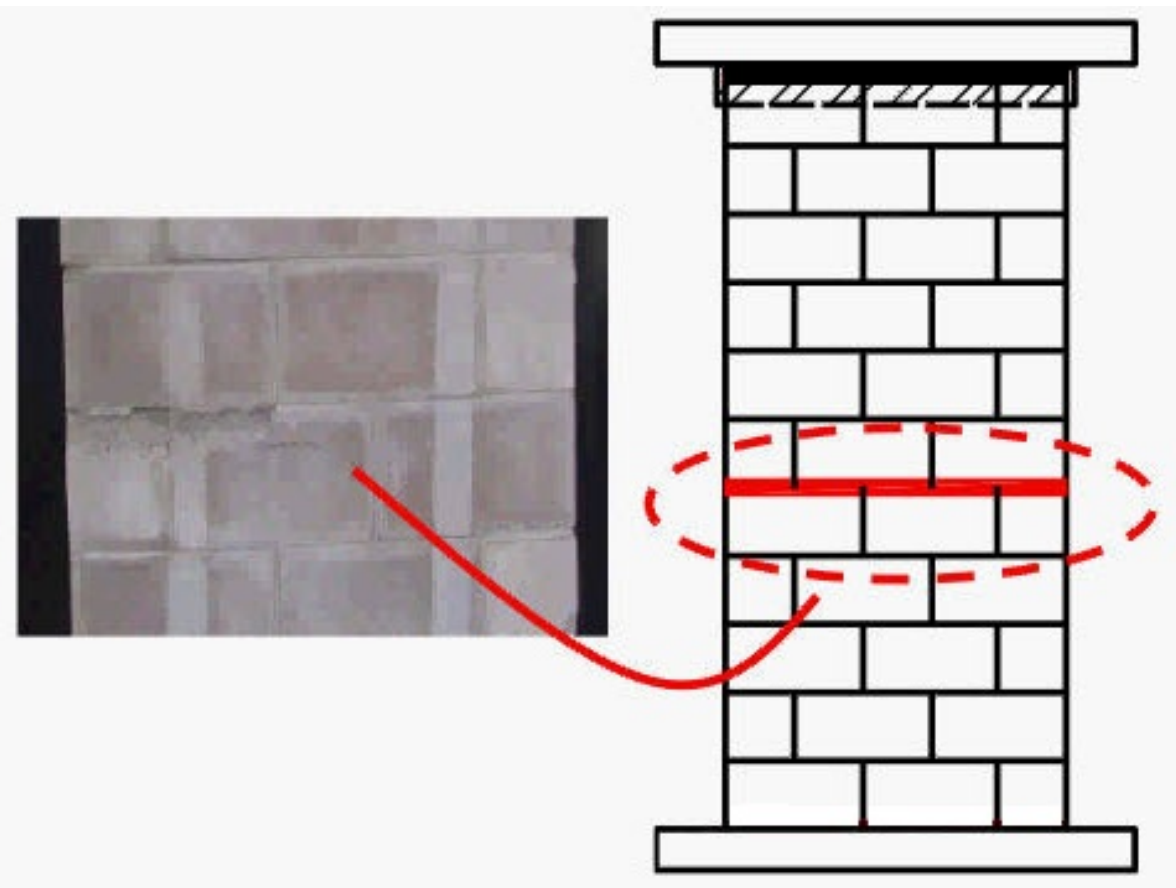

(c)

Fig. 18. Post-blast observations of W4 after shot: simulation (a) back face maximum principal plastic strain; (b) deformed mesh at maximum deflection; test (c) crack patterns [19]. 


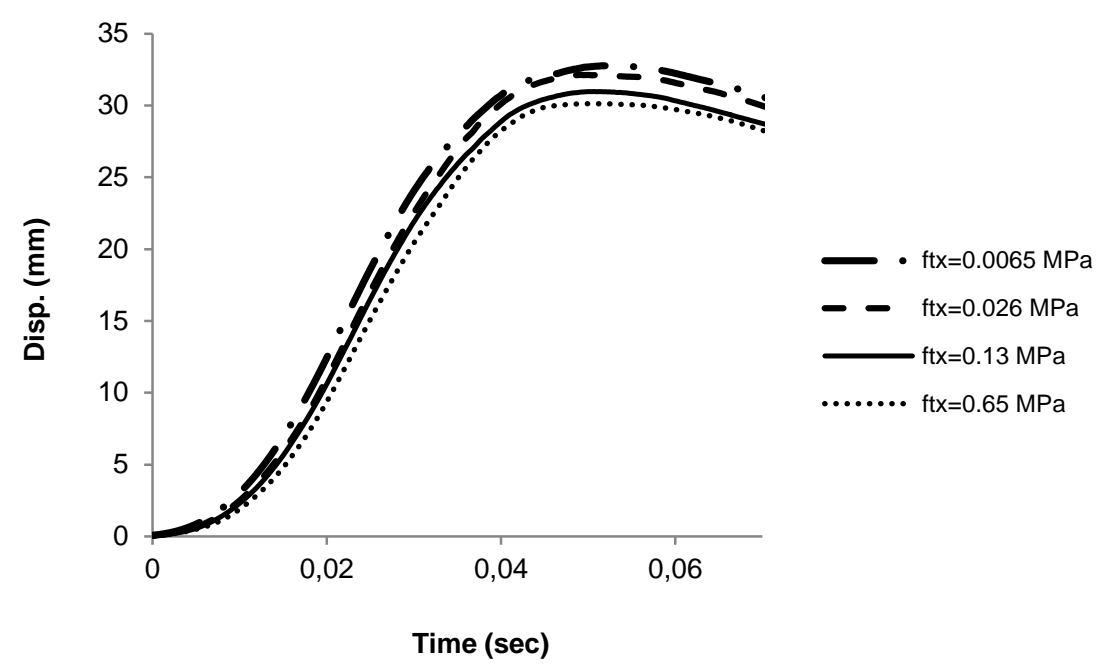

Fig. 19. Displacement vs. time diagram of URP1with different tensile strengths in horizontal direction. 


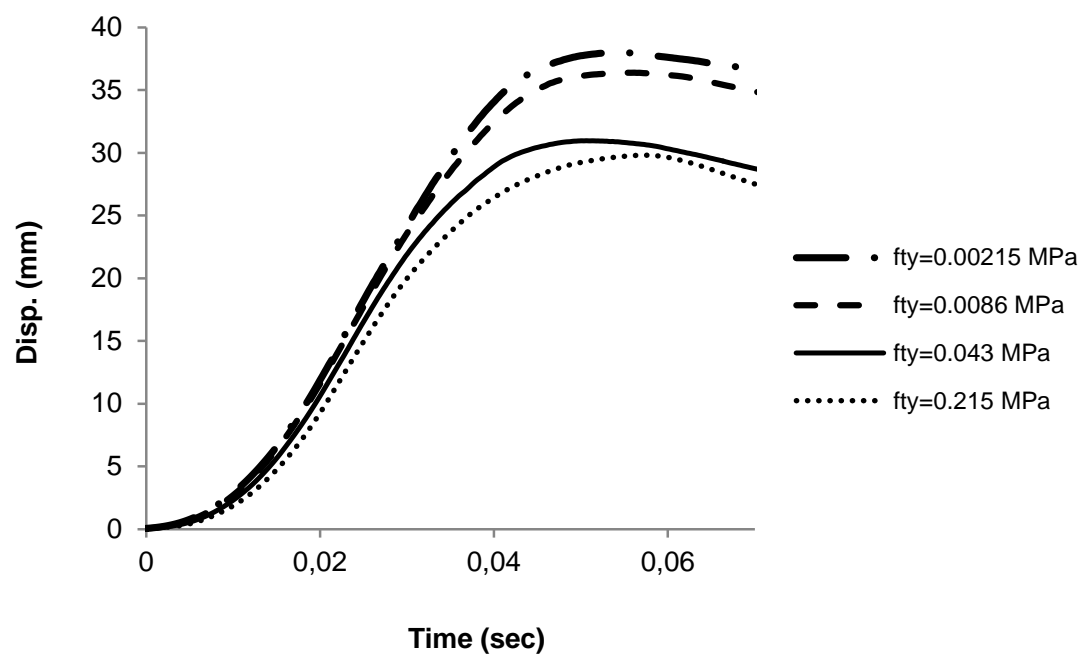

Fig. 20. Displacement vs. time diagram of URP1with different tensile strengths in vertical direction. 


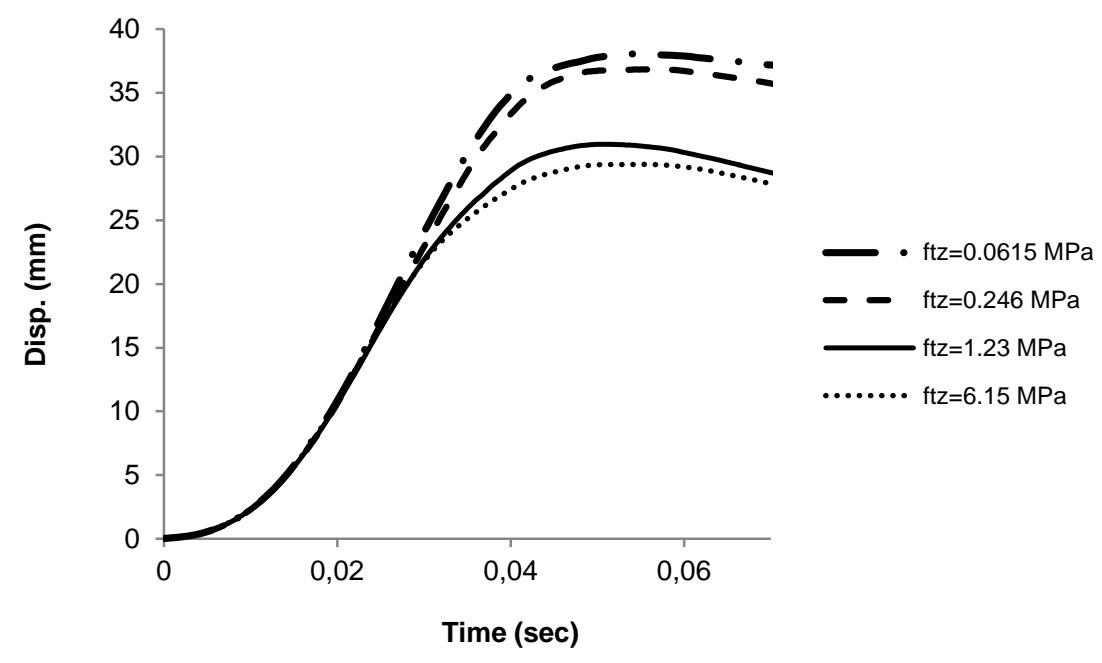

Fig. 21. Displacement vs. time diagram of URP1with different tensile strengths in out of plane direction. 

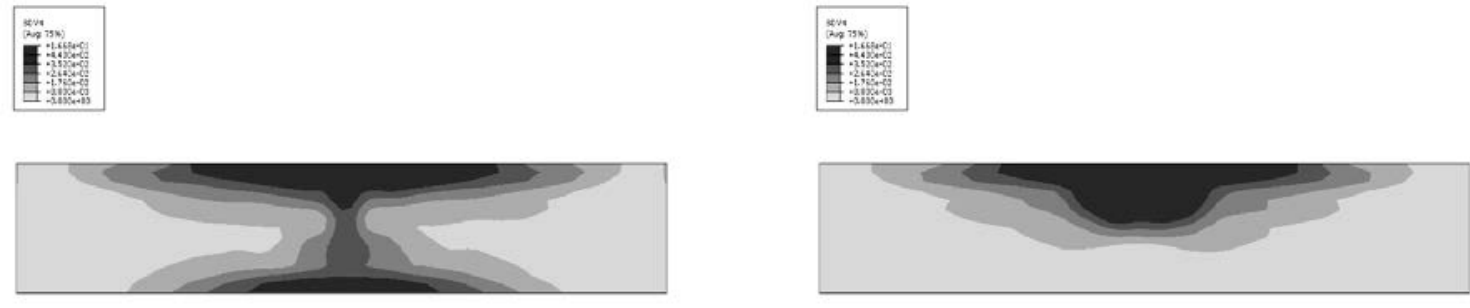

$\stackrel{1}{\circ}$

(a)

$\stackrel{1}{\circ}$

(b)
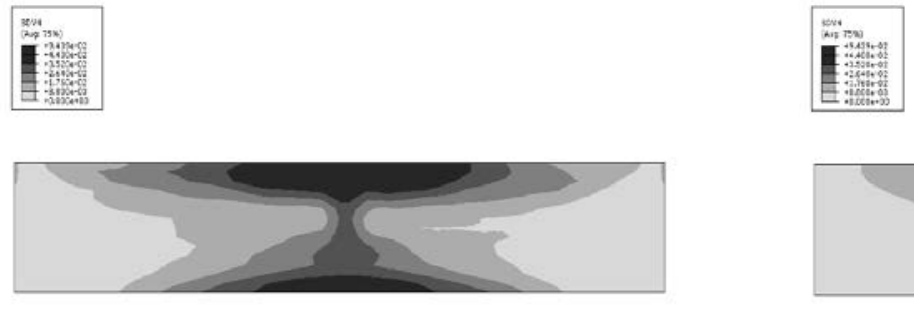

$\stackrel{5}{\circ}$

(c)

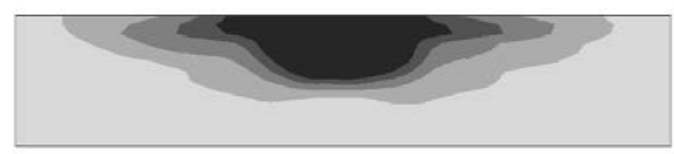

.

(d)
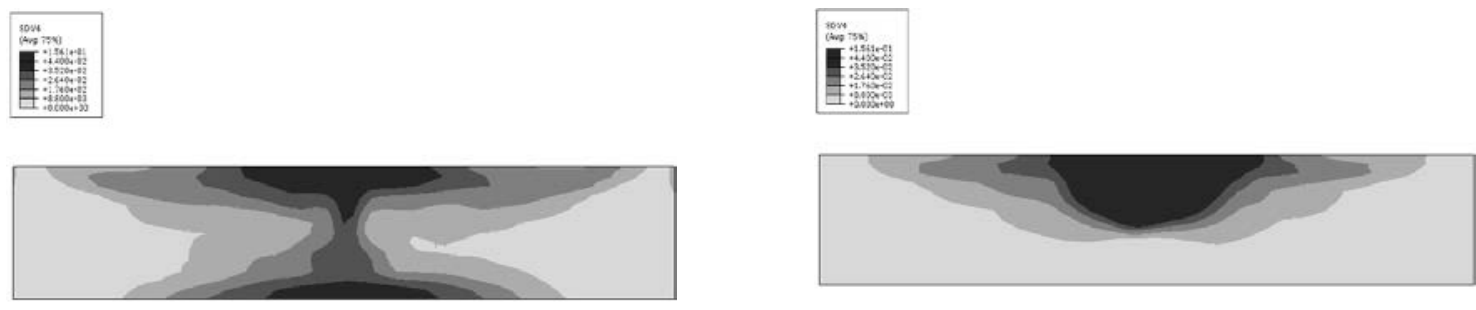

L.

(e)

$=$

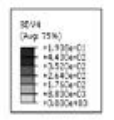

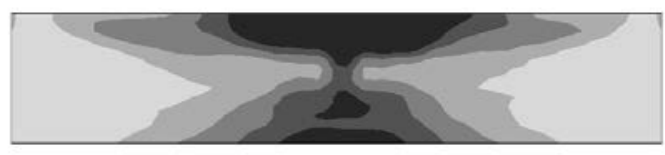

$\stackrel{\lrcorner}{\circ}$ $(f)$
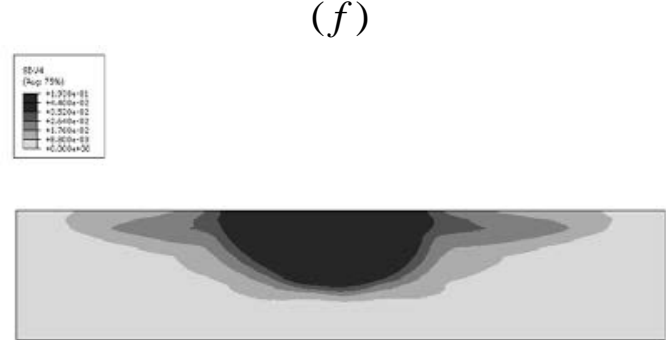

.

(h)

Fig. 22. Crack patterns of URP1 at ultimate deflection with different tensile strengths in horizontal direction: $\mathrm{f}_{\mathrm{tx}}=0.0065 \mathrm{MPa}(\mathrm{a})$ front and (b) back face; $\mathrm{f}_{\mathrm{tx}}=0.026 \mathrm{MPa}$ (c) front and (d) back face; $\mathrm{f}_{\mathrm{tx}}=0.13 \mathrm{MPa}(\mathrm{e})$ front and (f) back face; $\mathrm{f}_{\mathrm{tx}}=0.65 \mathrm{MPa}$ (g) front and (h) back face. 


\section{1i}

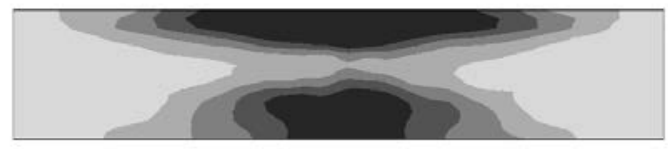

$\dot{\omega}$

(a)
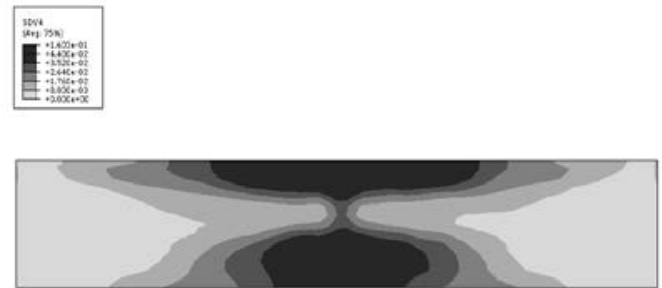

L.

(c)
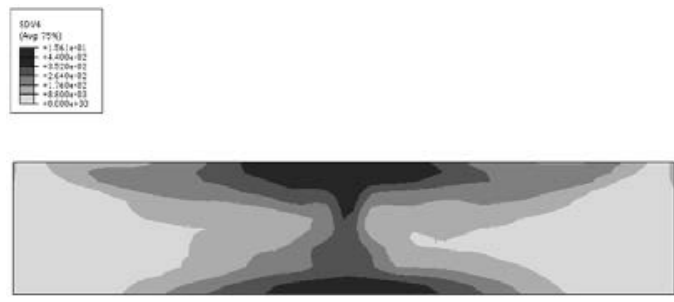

L.

(e)
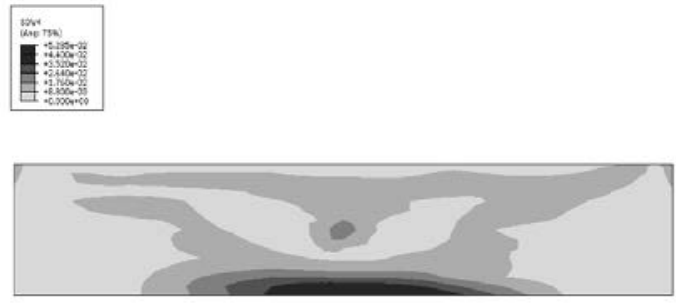

$\stackrel{1}{\circ}$

$(g)$

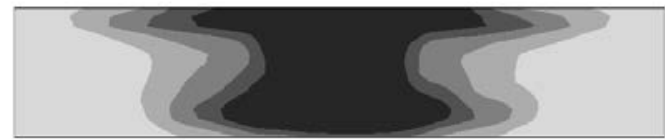

$\stackrel{1}{1}$

(b)
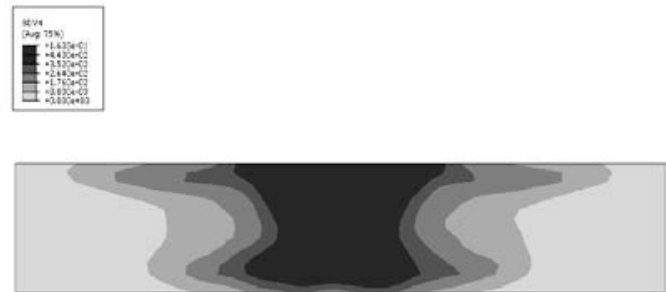

$\stackrel{1}{\circ}$

$(d)$
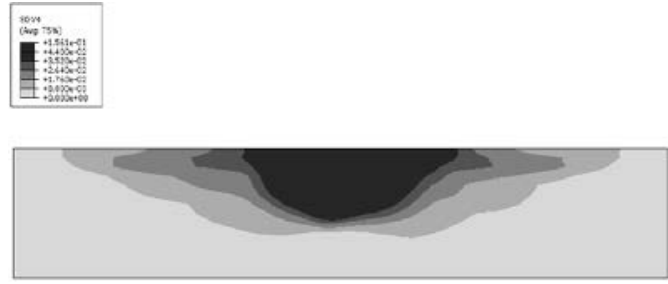

$=$

(f)
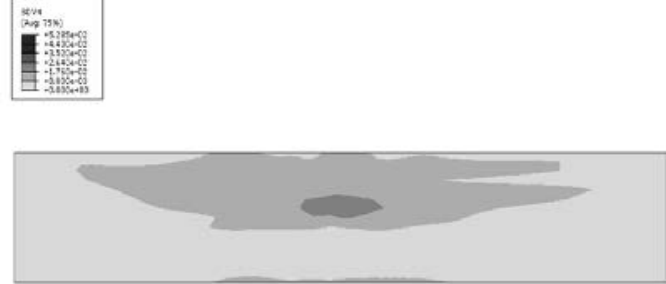

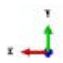

(h)

Fig. 23. Crack patterns of URP1 at ultimate deflection with different tensile strengths in vertical direction: $\mathrm{f}_{\mathrm{ty}}=0.00215 \mathrm{MPa}(\mathrm{a})$ front and (b) back face; $\mathrm{f}_{\mathrm{ty}}=0.0086 \mathrm{MPa}(\mathrm{c})$ front and (d) back face; $f_{t y}=0.043 \mathrm{MPa}(\mathrm{e})$ front and (f) back face; $\mathrm{f}_{\mathrm{ty}}=0.215 \mathrm{MPa}(\mathrm{g}$ ) front and (h) back face. 

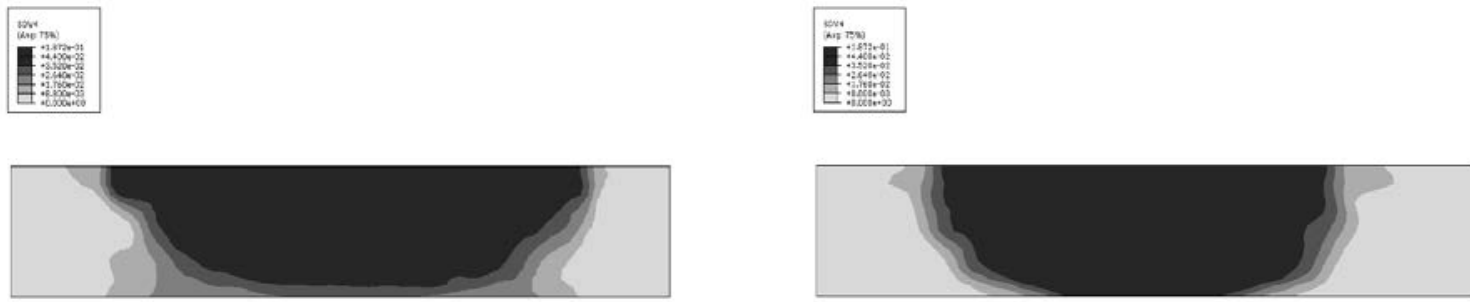

i.

(a)

(b)

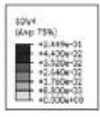

$\stackrel{1}{1}$
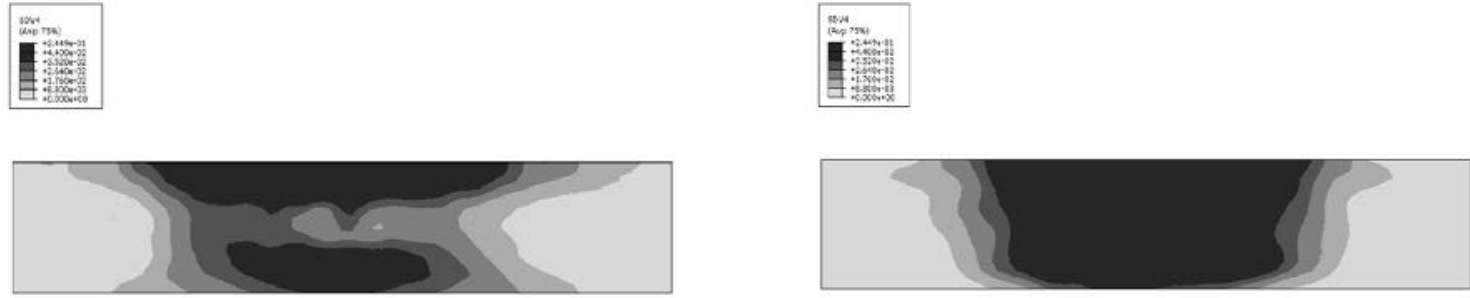

i.

(c)

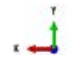

(d)
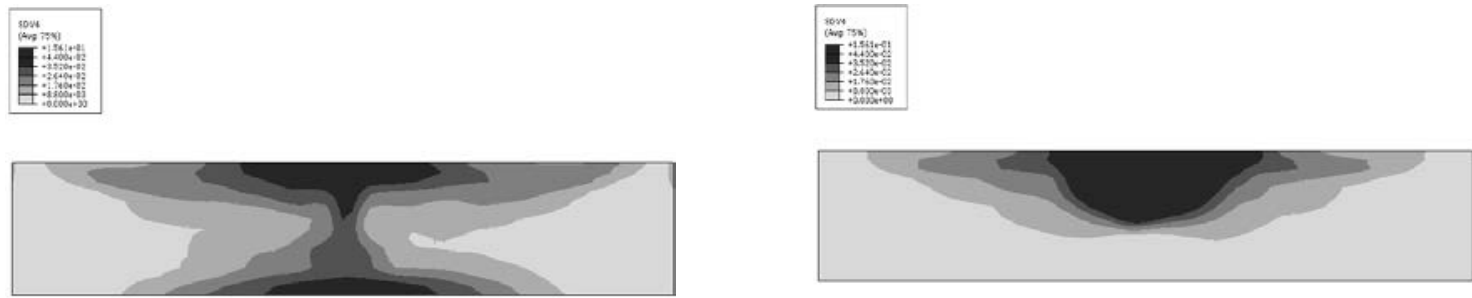

$=$

(e)

$(f)$
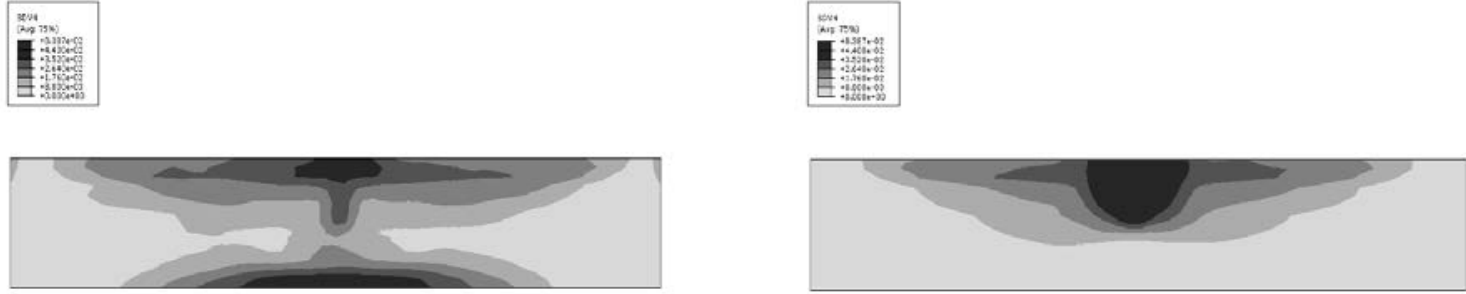

$\dot{L} \times$

(g)

(h)

Fig. 24. Crack patterns of URP1 at ultimate deflection with different tensile strengths in out of plane direction: $\mathrm{f}_{\mathrm{tz}}=0.0615 \mathrm{MPa}(\mathrm{a})$ front and (b) back face; $\mathrm{f}_{\mathrm{tz}}=0.246 \mathrm{MPa}(\mathrm{c})$ front and (d) back face; $\mathrm{f}_{\mathrm{tz}}=1.23 \mathrm{MPa}(\mathrm{e})$ front and (f) back face; $\mathrm{f}_{\mathrm{tz}}=6.15 \mathrm{MPa}(\mathrm{g})$ front and (h) back face. 


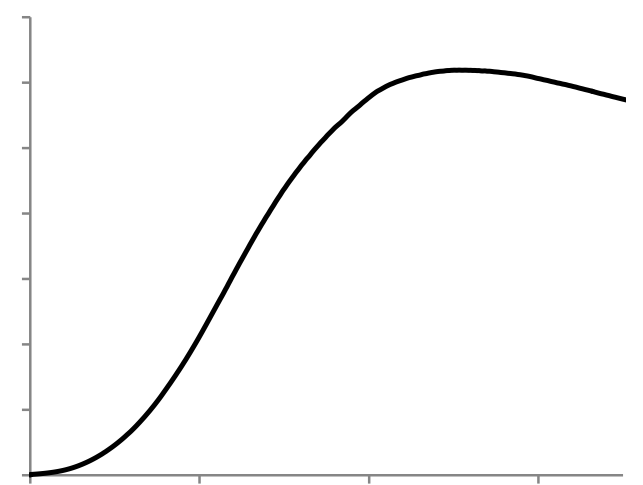

Fig. 25. Displacement vs. time responses of the wall URP1 with three wall thicknesses: (a) $\mathrm{t}=200 \mathrm{~mm}$; (b) $\mathrm{t}=250 \mathrm{~mm}$; (c) $\mathrm{t}=300 \mathrm{~mm}$. 

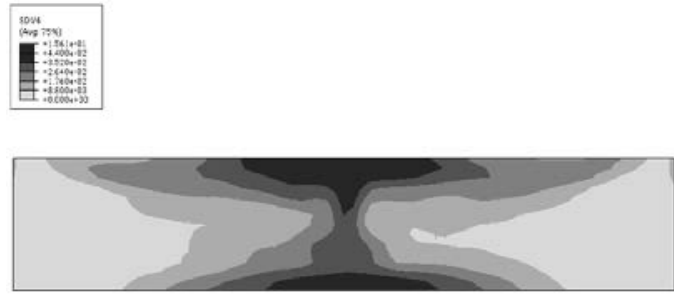

L.

(a)
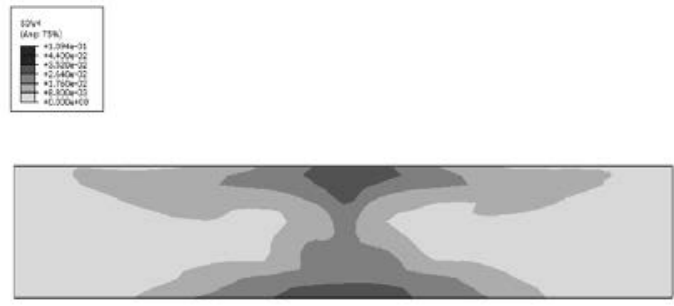

$\dot{L}$

(c)
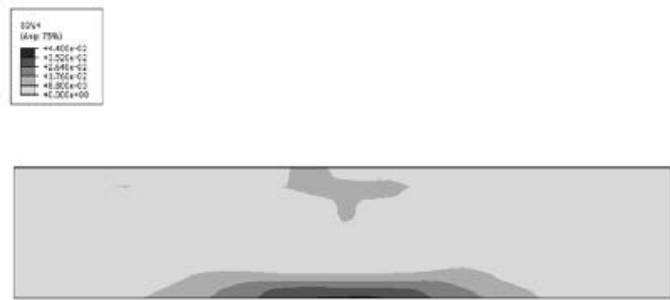

$i$

$(e)$
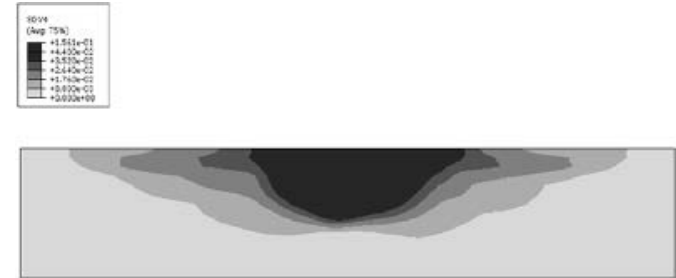

$=$

(b)
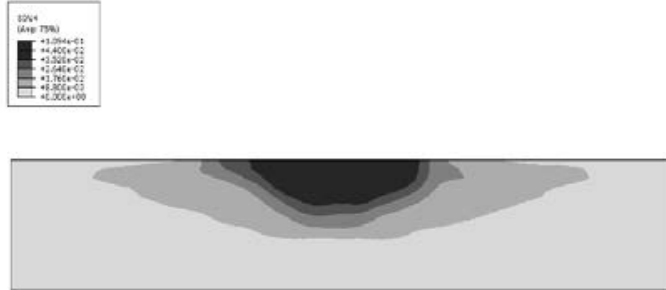

$=$

$(d)$
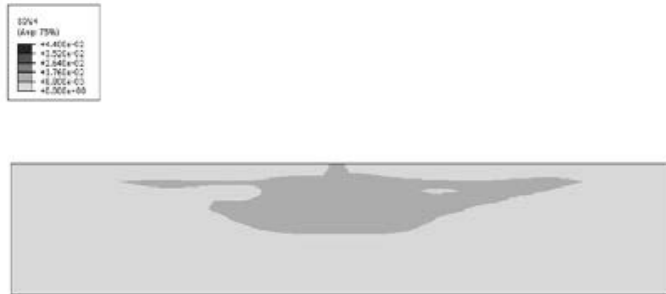

$=\stackrel{1}{0}$

$(f)$

Fig. 26. Crack patterns of URP1 at ultimate deflection with three different wall thicknesses: $\mathrm{t}=200 \mathrm{~mm}$ (a) front and (b) back face; $\mathrm{t}=250 \mathrm{~mm}$ (c) front and (d) back face; $\mathrm{t}=300 \mathrm{~mm}$ (e) front and (f) back face. 


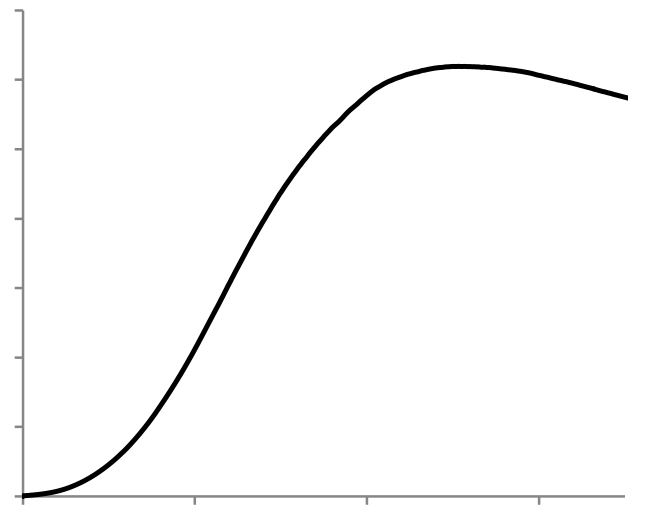

Fig. 27. Displacement vs. time responses of the wall URP1 for two different approaches: (a) different properties in integration points; (b) identical properties in integration points. 

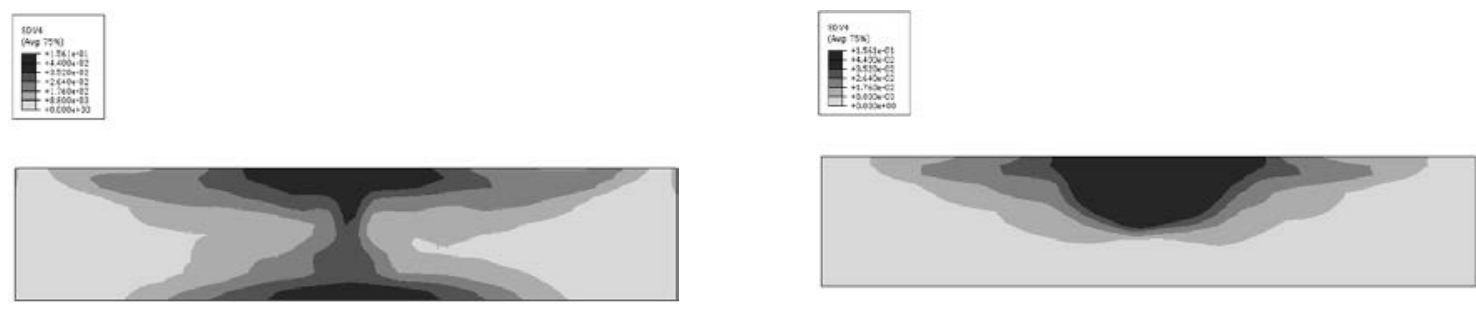

L.

(a)

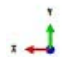

(b)
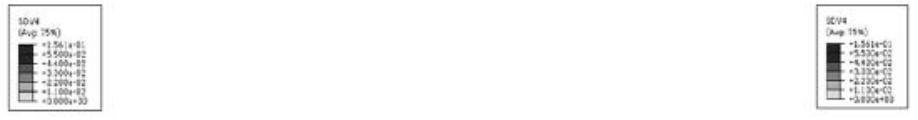

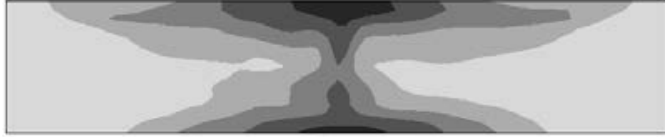

$\dot{L}=$

(c)

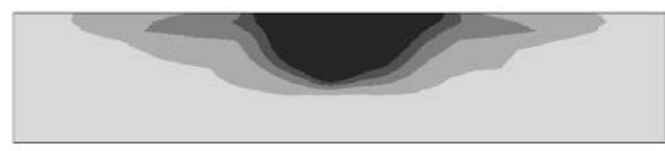

$(d)$

Fig. 28. Crack patterns of URP1 at ultimate deflection for two different approaches: different properties in integration points (a) front and (b) back face; identical properties in integration points (c) front and (d) back face. 


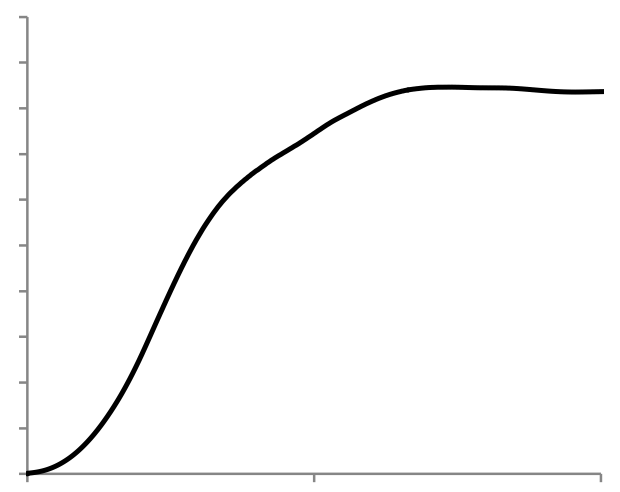

Fig. 29. Displacement vs. time responses of the wall URP1 for two different approaches against double applied impulse: (a) different properties in integration points; (b) identical properties in integration points. 

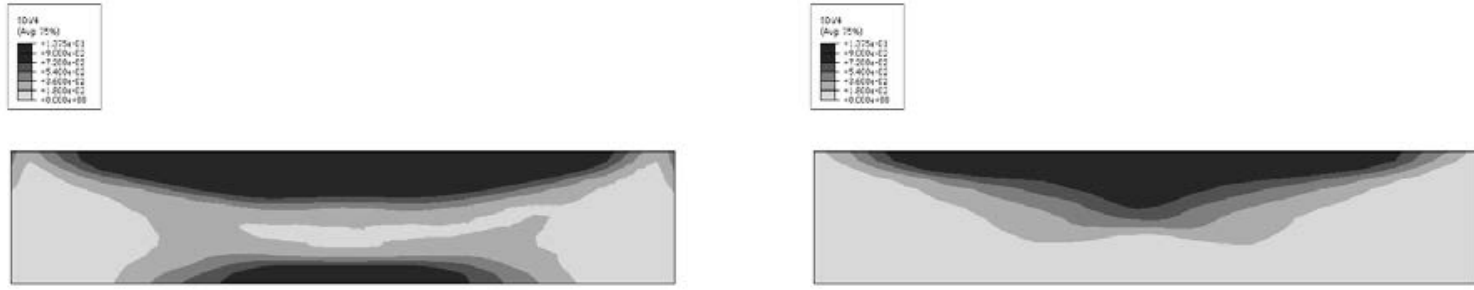

$\stackrel{\leftrightarrow}{\longrightarrow}$

$\times$

(a)

(b)
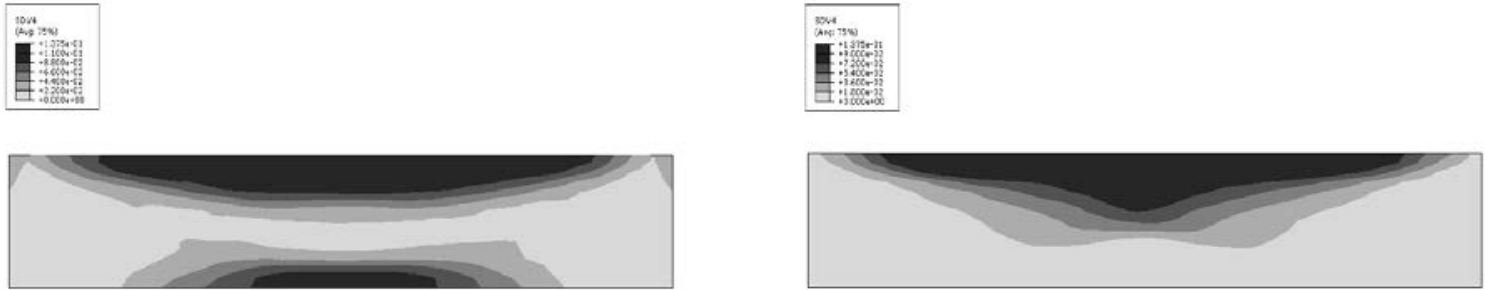

$\stackrel{x}{\perp}$

$=$

(c)

$(d)$

Fig. 30. Crack patterns of URP1 at ultimate deflection for two different approaches against different applied impulse: different properties in integration points (a) front and (b) back face; identical properties in integration points (c) front and (d) back face. 
Table 1

Elastic material properties for masonry and corresponding DIFs [17].

\begin{tabular}{cccc}
\hline & \multicolumn{3}{c}{ Elastic properties } \\
\cline { 2 - 4 } & $E_{x}$ & $E_{y}$ & $E_{z}$ \\
& $(G P a)$ & $(G P a)$ & $(G P a)$ \\
\cline { 2 - 4 } & 4.5 & 1.8 & 2.8 \\
\hline Strain rate & $D I F$ & $D I F$ & $D I F$ \\
\hline $2 E-5$ & 1 & 1 & 1 \\
\hline 15 & 1.52 & 1.52 & 1.52 \\
\hline 75 & 1.91 & 1.91 & 1.91 \\
\hline 150 & 2.08 & 2.08 & 2.08 \\
\hline
\end{tabular}


Table 2

Inelastic material properties for masonry and corresponding DIFs [17].

\begin{tabular}{|c|c|c|c|c|c|c|c|c|c|c|c|c|c|}
\hline & \multicolumn{6}{|c|}{ Tension } & \multicolumn{7}{|c|}{ Compression } \\
\hline & $\begin{array}{c}f_{t x} \\
(M P a)\end{array}$ & $\begin{array}{c}f_{t y} \\
(M P a)\end{array}$ & $\begin{array}{c}f_{t z} \\
(M P a)\end{array}$ & $\begin{array}{c}G_{f t x} \\
(N / m)\end{array}$ & $\begin{array}{c}G_{f t y} \\
(\mathrm{~N} / \mathrm{m})\end{array}$ & $\begin{array}{c}G_{f t z} \\
(N / m)\end{array}$ & $\begin{array}{c}f_{m x} \\
(M P a)\end{array}$ & $\begin{array}{c}f_{m y} \\
(\mathrm{MPa})\end{array}$ & $\begin{array}{c}f_{m z} \\
(M P a)\end{array}$ & $\begin{array}{l}G_{f C X} \\
(N / m)\end{array}$ & $\begin{array}{c}G_{f c y} \\
(N / m)\end{array}$ & $\begin{array}{c}G_{f c z} \\
(\mathrm{~N} / \mathrm{m})\end{array}$ & $k_{p}$ \\
\hline & 0.130 & 0.043 & 1.230 & 3.12 & 0.52 & 72 & 21.5 & 8.6 & 12.3 & 22580 & 13760 & 19740 & $\begin{array}{c}3.2 \mathrm{E}- \\
3\end{array}$ \\
\hline Strain & $D I F$ & $D I F$ & $D I F$ & $D I F$ & $D I F$ & $D I F$ & $D I F$ & $D I F$ & $D I F$ & $D I F$ & $D I F$ & $D I F$ & $D I F$ \\
\hline rate & $f_{t x}$ & $f_{t y}$ & $f_{t z}$ & $G_{f t x}$ & $G_{f t y}$ & $G_{f t z}$ & $f_{m x}$ & $f_{m y}$ & $f_{m z}$ & $G_{f c x}$ & $G_{f c y}$ & $G_{f c z}$ & $k_{p}$ \\
\hline $2 \mathrm{E}-5$ & 1 & 1 & 1 & 1 & 1 & 1 & 1 & 1 & 1 & 1 & 1 & 1 & 1 \\
\hline 15 & 1.44 & 1.44 & 1.44 & 1.87 & 1.87 & 1.87 & 1.44 & 1.44 & 1.44 & 1.87 & 1.87 & 1.87 & 1.09 \\
\hline 75 & 1.89 & 1.89 & 1.89 & 2.63 & 2.63 & 2.63 & 1.89 & 1.89 & 1.89 & 2.63 & 2.63 & 2.63 & 1.2 \\
\hline 150 & 2.09 & 2.09 & 2.09 & 2.96 & 2.96 & 2.96 & 2.09 & 2.09 & 2.09 & 2.96 & 2.96 & 2.96 & 1.24 \\
\hline
\end{tabular}


Table 3

Elastic material properties for masonry parapets [17].

\begin{tabular}{|c|c|c|c|c|}
\hline \multirow[t]{3}{*}{ Wall } & \multicolumn{4}{|c|}{ Elastic properties } \\
\hline & $E_{X}$ & $E_{y}$ & $E_{z}$ & $v$ \\
\hline & $(G P a)$ & $(G P a)$ & $(G P a)$ & \\
\hline URP1 & 4.5 & 1.8 & 2.8 & 0.2 \\
\hline URP2 & 4.5 & 1.8 & 7.9 & 0.2 \\
\hline
\end{tabular}


Table 4

Inelastic material properties for masonry parapets [17].

\begin{tabular}{|c|c|c|c|c|c|c|c|c|c|c|c|c|c|}
\hline \multirow[t]{2}{*}{ Wall } & \multicolumn{6}{|c|}{ Tension } & \multicolumn{7}{|c|}{ Compression } \\
\hline & $\begin{array}{c}f_{t x} \\
(\mathrm{MPa})\end{array}$ & $\begin{array}{c}f_{t y} \\
(M P a)\end{array}$ & $\begin{array}{c}f_{t z} \\
(\mathrm{MPa})\end{array}$ & $\begin{array}{c}G_{f t x} \\
(N / m)\end{array}$ & $\begin{array}{c}G_{f t y} \\
(N / m)\end{array}$ & $\begin{array}{c}G_{f t z} \\
(\mathrm{~N} / \mathrm{m})\end{array}$ & $\begin{array}{c}f_{m x} \\
(M P a)\end{array}$ & $\begin{array}{c}f_{m y} \\
(M P a)\end{array}$ & $\begin{array}{c}f_{m z} \\
(M P a)\end{array}$ & $\begin{array}{c}G_{f c x} \\
(N / m)\end{array}$ & $\begin{array}{l}G_{f c y} \\
(N / m)\end{array}$ & $\begin{array}{c}G_{f c z} \\
(N / m)\end{array}$ & $k_{p}$ \\
\hline URP1 & 0.130 & 0.043 & 1.230 & 3.12 & 0.52 & 72 & 21.5 & 8.6 & 12.3 & 22580 & 13760 & 19740 & $3.2 \mathrm{E}-3$ \\
\hline URP2 & 0.130 & 0.043 & 3.740 & 3.12 & 0.52 & 217 & 21.5 & 8.6 & 37.4 & 22580 & 13760 & 26050 & $3.2 \mathrm{E}-3$ \\
\hline
\end{tabular}


Table 5

Masonry damage criteria (UFC-3-340-02, 2008) [18].

\begin{tabular}{ccc}
\hline \multirow{2}{*}{ Element } & Yield pattern & Maximum support rotation $\left(^{\circ}\right)$ \\
\hline \multirow{2}{*}{ Masonry Reusable } & One-way & 0.5 \\
\cline { 2 - 3 } & Two-way & 0.5 \\
Masonry Non-reusable & One-way & 1.0 \\
\cline { 2 - 3 } & & 2.0 \\
\hline
\end{tabular}


Table 6

Experimental matrix of free-field blast tests [19].

\begin{tabular}{ccc}
\hline Specimen & Charge weight $(\mathrm{kg}$ TNT) & Stand-off distance $(\mathrm{m})$ \\
\hline W1 & 50 & 15 \\
W2 & 100 & 15 \\
W3 & 150 & 15 \\
W4 & 200 & 15 \\
W5 & 250 & 15 \\
\hline
\end{tabular}


Table 7

Elastic material properties for masonry walls [19].

\begin{tabular}{|c|c|c|c|c|}
\hline \multirow[t]{2}{*}{ Wall } & \multicolumn{4}{|c|}{ Elastic properties } \\
\hline & $E_{X}(G P a)$ & $E_{y}(G P a)$ & $E_{z}(G P a)$ & $v$ \\
\hline $\begin{array}{c}\text { W1, W2, W3, } \\
\text { W4, W5 }\end{array}$ & 12.9 & 22.87 & 25 & 0.2 \\
\hline
\end{tabular}


Table 8

Inelastic material properties for masonry walls [19].

\begin{tabular}{|c|c|c|c|c|c|c|c|c|c|c|c|c|c|}
\hline \multirow[t]{2}{*}{ Wall } & \multicolumn{6}{|c|}{ Tension } & \multicolumn{7}{|c|}{ Compression } \\
\hline & $\begin{array}{c}f_{t x} \\
(M P a)\end{array}$ & $\begin{array}{c}f_{t y} \\
(\mathrm{MPa})\end{array}$ & $\begin{array}{c}f_{t z} \\
(\mathrm{MPa})\end{array}$ & $\begin{array}{c}G_{f t x} \\
(N / m)\end{array}$ & $\begin{array}{c}G_{f t y} \\
(N / m)\end{array}$ & $\begin{array}{c}G_{f t z} \\
(\mathrm{~N} / \mathrm{m})\end{array}$ & $\begin{array}{c}f_{m x} \\
(M P a)\end{array}$ & $\begin{array}{c}f_{m y} \\
(\mathrm{MPa})\end{array}$ & $\begin{array}{c}f_{m z} \\
(M P a)\end{array}$ & $\begin{array}{l}G_{f c x} \\
(N / m)\end{array}$ & $\begin{array}{c}G_{f c y} \\
(N / m)\end{array}$ & $\begin{array}{c}G_{f c Z} \\
(N / m)\end{array}$ & $k_{p}$ \\
\hline $\begin{array}{c}\text { W1, W2, W3, } \\
\text { W4, W5 }\end{array}$ & 0.4 & 0.37 & 2.5 & 9.6 & 4.44 & 72.5 & 12.9 & 25.85 & 25 & 20640 & 41360 & 40000 & $\begin{array}{c}0.67 \mathrm{E}- \\
3\end{array}$ \\
\hline
\end{tabular}

